"This is the peer reviewed version of the following article: Synthesis 2016, 48, 3863-3878, which has been published in final form at DOI: 10.1055/s-0035-1562520. This article may be used for non-commercial purposes in accordance with the Terms and Conditions for Self-Archiving published by THIEME at https://www.thieme-connect.de/products/ejournals/abstract/10.1055/s-00351562520." 


\section{Substrate-Assisted Carbon Dioxide Activation as a Versatile Approach for Heterocyclic Synthesis}

\author{
Jeroen Rintjema \\ Arjan W. Kleij*a,b \\ a Institute of Chemical Research of Catalonia (ICIQ), the \\ Barcelona Institute of Science and Technology, Av. Països \\ Catalans 16, 43007 - Tarragona (Spain) \\ ${ }^{b}$ Catalan Institute of Research and Advanced Studies (ICREA), \\ Pg. Lluis Companys 23, 08010 - Barcelona (Spain). \\ * indicates the main/corresponding author. \\ akleij@iciq.es
}

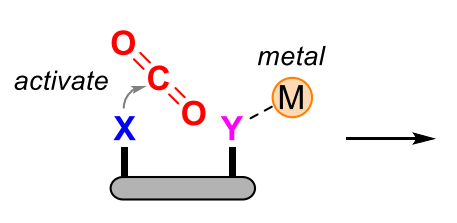

$\mathrm{CO}_{2}$ activation

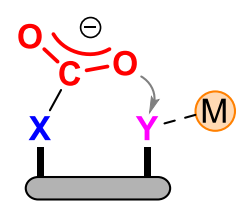

Cyclization

\begin{abstract}
Received:
Accepted:
Published online:

Abstract: The $\mathrm{CO}_{2}$ incorporation into substrates containing alcohol or amine functional groups displays interesting substrate-controlled reactivity, both in terms of providing milder reaction conditions and the potential towards new reactivity modes. Various heterocyclic structures can be prepared using such substrate-driven approach starting from functional derivatives of (homo)allylic and propargylic alcohols/amines, epoxy alcohols and hydroxy-oxetanes among others. This review summarizes the recent advances made in this area.

1. Introduction

2. Catalytic conversion of propargylic alcohols

3. Catalytic conversion of propargylic amines

4. (Homo)Allylic alcohol substrate conversions

5. Transformation of allylic amines

6. Epoxy alcohols/amines as substrates

7. Hydroxy oxetanes and azetidines scaffolds

8. Conversion of other substrates

9. Summary and outlook
\end{abstract}

Key words: amines - alcohols - carbon dioxide - heterocycles - homogeneous catalysis - substrate activation

\section{Introduction}

Ever since the beginning of the industrial revolution, the emission of carbon dioxide and other greenhouse gases into the atmosphere has increased drastically. The majority of this increase can be ascribed to industrial processes releasing annually billions of tons of $\mathrm{CO}_{2 .}{ }^{1}$ Increasing efforts are thus being made to potentially alleviate the $\mathrm{CO}_{2}$ emitted to the environment, and investigating new technologies to valorize this cheap and renewable carbon feed stock. ${ }^{2}$ Until recently, $\mathrm{CO}_{2}$ was mainly considered as an inert waste material that cannot be easily utilized in chemical conversions. Over the years, however, the synthetic potential of carbon dioxide as a carbon building block has been tremendously explored and many new transformations have now been developed. ${ }^{3}$ Such rejuvenated potential may positively influence the carbon footprint of (part of) our fossilfuel depending chemical processes. ${ }^{4}$ The utilization of $\mathrm{CO}_{2}$ as a $\mathrm{C} 1$ building block is notwithstanding challenging due to its intrinsic stability, and typically a catalytic method is required for its activation and conversion. ${ }^{5}$ In this respect, nature provides an interesting role model. Carbon dioxide activation can for instance be achieved by the enzyme carbonic anhydrase (CA) that catalyzes the hydration of $\mathrm{CO}_{2}$ with very high efficiency. The active site of this enzyme consists of a zinc center supported by three imidazole groups belonging to histidine residues (Figure 1).

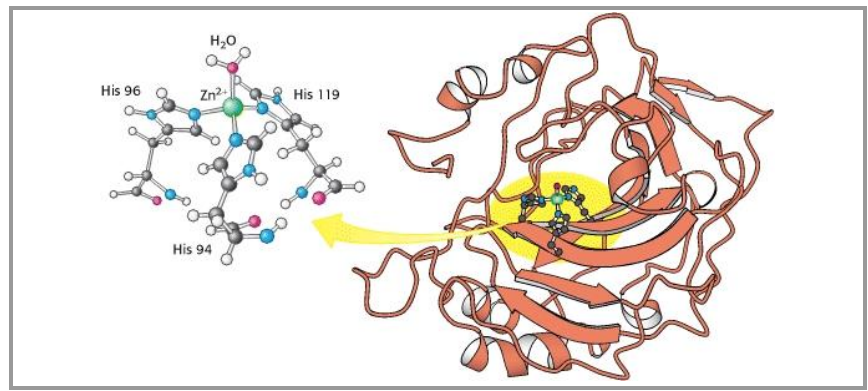

Figure 1: Carbonic anhydrase II containing a zinc center supported by three histidine residues (left) and its position within the enzyme (right). ${ }^{6}$

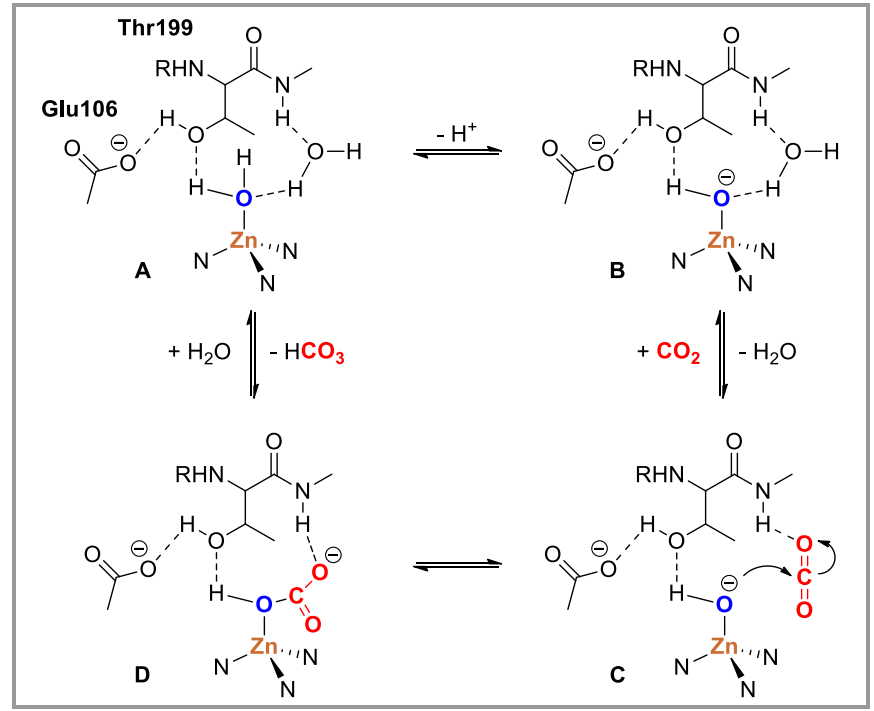

Scheme 1: Proposed mechanism of activation and hydration of $\mathrm{CO}_{2}$ by carbonic anhydrase. ${ }^{7}$ 
Earlier studies inspired by the $\mathrm{CO}_{2}$ activation potential of carbonic anhydrase focused on mimicking the enzyme's active site. Several zinc-based complexes have been prepared containing a zinc-ligated water molecule and nitrogen-based ligands that structurally resemble the histidine moieties. ${ }^{8}$

However, it remains a challenge to effectively mimic CA activity as it not only depends on the features of the active site but also on the surrounding enzyme pocket, i.e. the second coordination sphere. Subsequent research revealed an important role for the zinc-bound water molecule, which at physiological $\mathrm{pH}$ is partly present as a metal-bound hydroxide ion. This hydroxide ligand is the key element towards the catalytic hydration of carbon dioxide (Scheme 1). The first step in the catalytic hydration of $\mathrm{CO}_{2}$ by $\mathrm{CA}$ is the abstraction of a proton from the water molecule in (A) to form a zinc-bound hydroxide ion (B). In the next step carbon dioxide coordinates to form intermediate (C) followed by attack of the hydroxyl group leading to species (D). Release of the bicarbonate anion and coordination of another water molecule finally regenerates the starting CA complex (A).

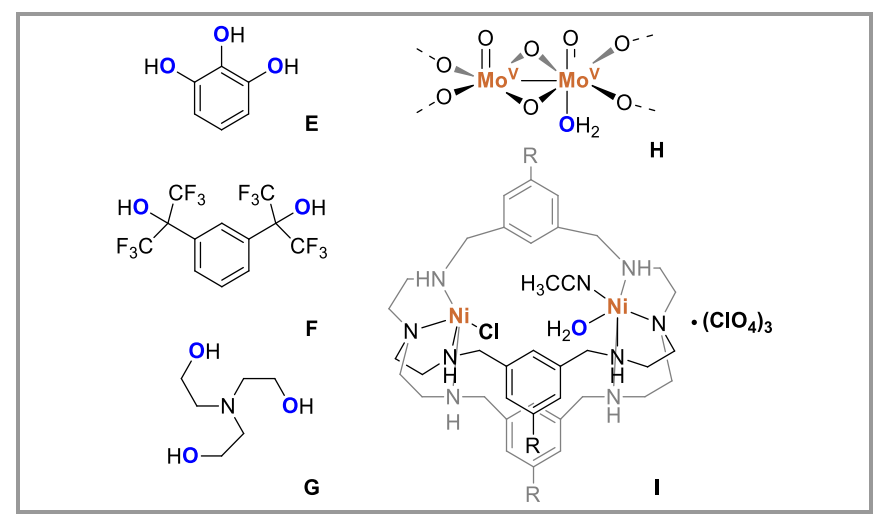

Figure 2: Various HBDs employed in the coupling of epoxides and carbon dioxide. $9,10 \mathrm{~b}$

Subsequent research on the activation of carbon dioxide has focused more on the particular function of the hydroxyl group, rather than on synthesizing complicated structural analogues of CA. Various research groups contributed towards this objective leading to the synthesis of both metal- ${ }^{9}$ and organo-based ${ }^{10}$ catalysts comprising a hydroxyl group (Figure 2) that is directly or indirectly involved in the conversion of $\mathrm{CO}_{2}$. Compelling evidence for the interaction/activation of carbon dioxide by alcohols to form alkyl carbonic acid species comes for instance from its reaction with diazodiphenylmethane. ${ }^{11}$ The latter is a compound that reacts with carboxylic acids forming related carbonate and ether species. Alcohols were found to react with diazodiphenylmethane in supercritical $\mathrm{CO}_{2}$ forming the aforementioned product, which suggests the intermediacy of a carbonic acid species. More recently the group of Stoddart investigated the properties of a metal-organic framework (MOF) consisting of cyclodextrin units. ${ }^{12}$ This MOF was capable of reversibly binding $\mathrm{CO}_{2}$ through its hydroxyl groups present in the cyclodextrin units, forming a carbonic acid species. Evidence for this formation was provided by solid state ${ }^{13} \mathrm{C}$ NMR, showing a diagnostic new peak at 158 ppm (cf., formation of a carbonate) upon exposure of the MOF to $\mathrm{CO}_{2}$.
Many (organo)catalysts in the area of $\mathrm{CO}_{2}$ conversion catalysis are based on phenol/alcohol derivatives such as 1,2,3trihydroxybenzene (pyrogallol; Figure 2, E) that serve as hydrogen bond donors (HBDs; other examples include $\mathbf{F}$ and $\mathbf{G}$ ) or are able to form a metal-hydroxide intermediate that can activate carbon dioxide ( $\mathbf{H}$ and $\mathbf{I})$. These systems have demonstrated high catalytic efficiency in the (indirect) activation of $\mathrm{CO}_{2}$ in the context of cyclic organic carbonate and carbamate formation. The preparation of cyclic organic carbonates (COCs) is among the most intensively studied transformations in the field of $\mathrm{CO}_{2}$ catalysis. ${ }^{13}$

Some of the major limitations in $\mathrm{CO}_{2}$ catalysis are the conversion of organic substrates under mild (ambient) conditions, broadening of the product scope and the development of more sustainable catalytic processes. Whereas the vast majority of the reported catalytic strategies towards $\mathrm{CO}_{2}$ conversion are purely metal-based, the use of substrate-directed $\mathrm{CO}_{2}$ activation remains to date underdeveloped. The incorporation of alcohol or amine functionalities in the substrate may assist in the activation of carbon dioxide preparing it thus for conversion into value-added organic structures. Not only can this facilitate the coupling of $\mathrm{CO}_{2}$ with the substrate under milder conditions, but it also opens up new pathways to access new products that would be difficult to synthesize by any conventional methods. Prospectively, substrates equipped with suitable $\mathrm{CO}_{2}$-activating groups may hold promise to further widen the scope of functionalized organics that can be derived from $\mathrm{CO}_{2}$ and help to increase its synthetic value. In this review the focus will be on the latest developments in this sub-area of $\mathrm{CO}_{2}$ catalysis describing the categories of substrates that have been successfully utilized in substrate-controlled $\mathrm{CO}_{2}$ conversion approaches towards the formation of various heterocyclic structures. In each separate section, the key contributions are highlighted together with the mechanistic understanding of the involved organic transformations.

\section{Catalytic conversion of propargylic alcohols}

Among the possible scaffolds that can be used for substrateassisted activation of carbon dioxide, propargylic alcohols are by far the most widely considered. To date many contributions have been made involving the cyclization of propargylic alcohols in the presence of $\mathrm{CO}_{2}$ typically leading to the formation of $\alpha$-alkylidene cyclic carbonates. These carbonates are important building blocks for several post-synthetic transformations, ${ }^{14}$ including the formation of carbamates and ureas. ${ }^{15}$

\subsection{Metal catalysts}

The first example of a coupling reaction between a propargylic alcohol and carbon dioxide was already reported in $1961^{16}$ followed up by a contribution from Laas et al. twenty years later. ${ }^{17}$ Both catalytic processes use copper iodide (CuI) as the catalyst in combination with triethylamine $\left(\mathrm{NEt}_{3}\right)$ as base (Scheme 2). Other early examples of catalytic systems that can mediate similar conversions employ different metals such as palladium, ${ }^{18}$ cobalt ${ }^{19}$ and ruthenium. ${ }^{20}$ 


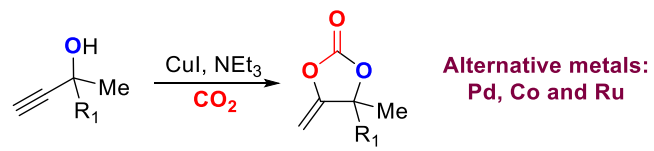

Scheme 2: Copper catalyzed formation of $\alpha$-alkylidene cyclic carbonates.

The popularity of copper based systems can be ascribed to its availability, low cost and ease of use in catalysis. ${ }^{21}$ However, one of the challenges in these copper catalyzed cyclization reactions was the conversion of propargylic alcohols incorporating internal alkynes. This problem was addressed in a recent contribution from Qi and Jiang22 using a combination of $\mathrm{CuI}$ and $\mathrm{N}, \mathrm{N}$-diisopropylethylamine (DIPEA). Interestingly, this recent work demonstrated not only the conversion of such propargylic alcohols (Scheme 3, 1) into the targeted cyclic carbonates 2, but also delivered a new route to iodoalkylidene derivatives $\mathbf{3}$ under appropriate and selected reaction conditions.

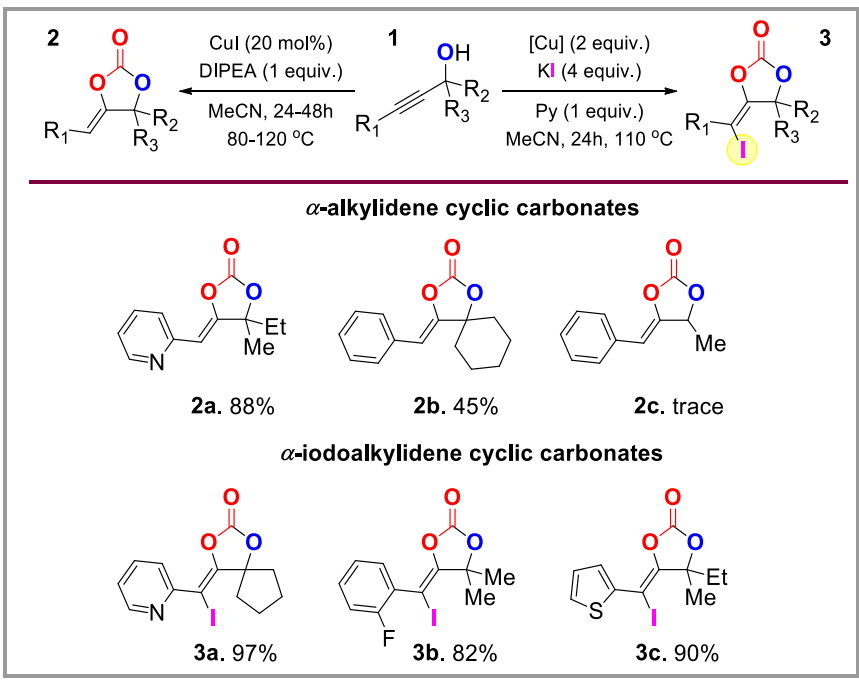

Scheme 3: Synthesis of the conventional $\alpha$-alkylidene cyclic carbonates (left) and the $\alpha$-iodoalkylidene derivatives (right). Below representative examples of the product scope achieved in either type of conversion.

Incorporation of iodine into the carbonate structure gives the (E)-iodoalkylidene cyclic carbonates, of which the synthesis is related to that reported by Minakata in the formation of iodocarbonates (see section on allylic alcohols conversion). ${ }^{23} \mathrm{~A}$ different iodine source is used in this case, which is generated in situ from copper and iodide salts.

Scheme 4 displays the proposed reaction mechanism, which starts with the activation of $\mathrm{CO}_{2}$ by the propargylic alcohol group and coordination of copper to the alkyne 4. Cyclization occurs through attack of the carbonate anion on the activated triple bond forming intermediate $\mathbf{5}$. Although this vinyl-metal species was not isolated, similar intermediates have been proposed to exist using, for instance, silver-based catalysts. ${ }^{24}$ Simple protonation of the copper-bound intermediate gives the cyclic carbonate 6 through path a. The other pathway involves the prior formation of an $\mathrm{I}_{3}$ anion coupled with the reduction of $\mathrm{Cu}(\mathrm{II})$ to $\mathrm{Cu}(\mathrm{I})$, after which iodine replaces copper to form the iodinated product 7. Several observations support this proposed reaction mechanism. When the reaction is performed with $\mathrm{I}_{2}$ (i.e., a different source of electrophilic iodine) a mixture of products was obtained. Another mechanistic clue arose from the reduction of copper during the catalytic cycle, which is later re-oxidized by oxygen from the air. If the reaction is performed under anaerobic conditions, only $15 \%$ of $\mathbf{7}$ is obtained together with formation of 6 as the major product.

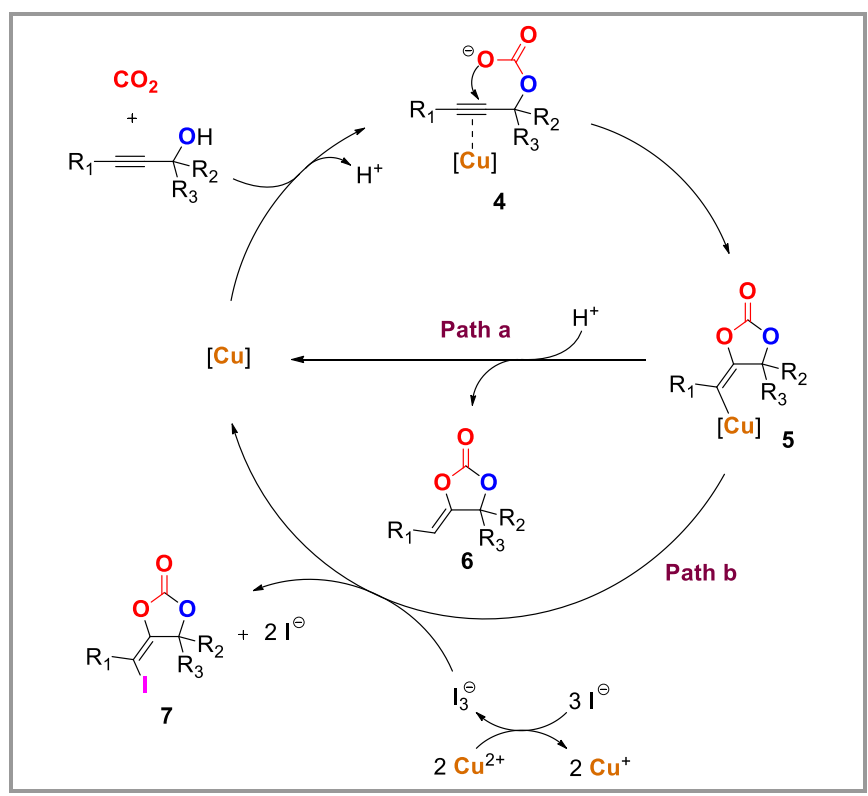

Scheme 4: Proposed reaction mechanism of the formation of alkylidene cyclic carbonates (path a) and its iodinated derivatives (path b).

Under the conditions outlined in Scheme 3 (with below part of the product scope; compounds $\mathbf{2 a - b}$ and $\mathbf{3 a - c}$ ) and following the two pathways displayed in Scheme 4, two different types of products can thus be prepared The $\alpha$-alkylidene cyclic carbonates are typically obtained in moderate to high yields depending on the substrate substitution pattern. The iodinated variants are generally acquired in good to excellent yields of up to $97 \%$ and cover a wide substrate scope. A limitation of this protocol is the necessity for tertiary propargylic alcohols, as the use of primary or secondary alcohols (Scheme 3, 2c) only leads to trace amounts of product. A clear advantage of this method is the availability and cost of the copper catalyst and iodine salts that are used. However, the reactions are not really atom- and waste-efficient producing two equivalents of copper salt and requiring four equivalents of $\mathrm{KI}$.

Reaction conditions associated to the use of copper based chemistry discussed above typically involve high temperatures (around $100^{\circ} \mathrm{C}$ ) and high pressures of $\mathrm{CO}_{2}$ ( 40 bar). The quest for catalytic systems that could convert these propargylic alcohols under milder conditions led the group of Yamada to use silverbased catalysts. In 2007 they reported on the combined use of silver acetate (AgOAc) and DBU (1,8-diazabicyclo-undec-7-ene) in the coupling of $\mathrm{CO}_{2}$ with propargylic alcohols. ${ }^{24} \mathrm{~A}$ variety of substrates containing internal alkynes could be converted under mild conditions $\left(25^{\circ} \mathrm{C}, 10\right.$ bar $\left.\mathrm{CO}_{2}\right)$. These conversions at ambient temperature opened up the possibility for enantioselective carbon dioxide incorporation. Three years after their initial publication, Yamada et al. reported on the enantioselective coupling of $\mathrm{CO}_{2}$ with bis-propargylic alcohols (Scheme 5). ${ }^{25}$

DBU was not used for the asymmetric catalysis reactions, as it was expected that it strongly coordinates to the silver center 
and thus would negatively affect the asymmetric conversion of the propargylic alcohol. After optimization of the reaction conditions ( $3 \mathrm{~mol} \%$ AgOAc, $1 \mathrm{~mol} \%$ of ligand $\mathbf{L}$ at $0^{\circ} \mathrm{C}$ ) the product (9) depicted in Scheme 5 was obtained in an excellent yield of $98 \%$ and high ee (92\%). Various groups are tolerated in the position next to the alcohol $\left(\mathrm{R}^{2}\right)$ giving the respective products in similar high yields. When too large steric bulk was introduced, however, the yield dropped to $58 \%\left(11 \mathrm{c}, \mathrm{R}^{2}=\mathrm{tBu}\right)$ even when using extended reaction times. Several other substituted phenyls and allyl-substituted propargylic alcohols $\mathbf{1 0}$ yielded the cyclic carbonates $\mathbf{1 1}$ in good yields and high ee. Benzyl groups attached to the alkyne units resulted in fast reactions though with significant loss of stereoselectivity resulting in $<50 \% e e$.

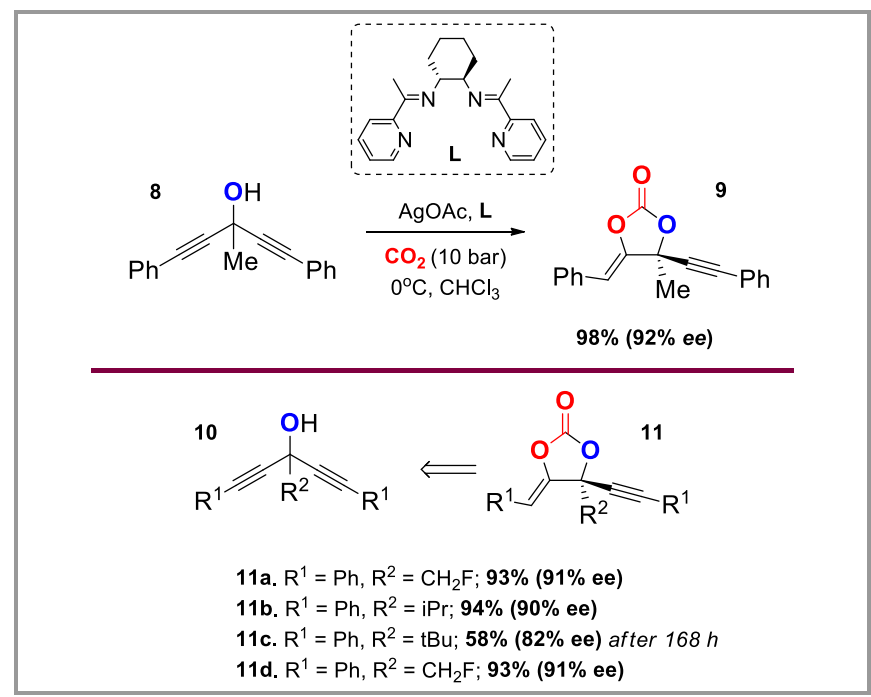

Scheme 5: Catalytic system based on AgOAc and a chiral Schiff base reported by Yamada for the asymmetric synthesis of carbonates 11

In the years following this seminal work, silver has maintained its importance as a catalyst in the formation of $\alpha$ alkylidene cyclic carbonates from propargylic alcohols. Several systems based on silver have been developed recently, 26 including the work from Liu et al. on porous organic polymers ${ }^{27}$ and contributions from the group of He. ${ }^{28}$ Other metals have also been employed successfully, including tungstate ${ }^{29}$ and zinc. ${ }^{30}$ Further information on metal catalyzed cyclization of propargylic alcohols with $\mathrm{CO}_{2}$ can be found in other recent overviews. ${ }^{31}$

\subsection{Organocatalysts}

The first example of organocatalyzed $\mathrm{CO}_{2}$ incorporation into propargylic alcohol substrates was published in 1989 by the group of Dixneuf. ${ }^{32}$ They found that simple tributylphosphine $\left(\mathrm{PBu}_{3}\right)$ effectively catalyzes the formation of the cyclic carbonate product at $50^{\circ} \mathrm{C}$ giving almost quantitative conversion after $20 \mathrm{~h}$. In the years after their initial publication, they further developed the phosphine catalyzed coupling of $\mathrm{CO}_{2}$ and propargylic alcohols. $^{33}$ Recently, a contribution from the group of Ikariya demonstrated the combination of phosphine catalysis and a supercritical $\mathrm{CO}_{2} \quad\left(\mathrm{sc}-\mathrm{CO}_{2}\right)$ medium to facilitate similar reactions. ${ }^{34}$ Scheme 6 reports part of the substrate scope performed under the optimal conditions $\left(\mathrm{sc}-\mathrm{CO}_{2}\right)$ using $5 \mathrm{~mol} \%$ of $\mathrm{PBu}_{3}$ as an organocatalyst. Both terminal and internal propargylic alcohols (12) could be converted with good to excellent yields (cf., products 13a-b). Several electron withdrawing substituents were tolerated on the aromatic ring (cf., products 13c-d), though electron donating groups led to very poor results. Lower yields were obtained when a tolyl group was present and no product formation was observed in the case of a para-methoxyaryl substituent (cf., intended formation of 13e). Changing the substitution pattern near the alcohol also gave access to cyclic carbonate formation in good yield (compound 13f, $\mathrm{R}^{2}$ = c-hexyl; 74\%). However, the substrate scope seems to be restricted to tertiary alcohols only, as no product was obtained for primary or secondary alcohols (example: formation of $\mathbf{1 3 g}$ ). This is a common observation in the area of propargylic alcohol $/ \mathrm{CO}_{2}$ couplings, and its origin has been proposed to be a result of the gem-dialkyl effect. ${ }^{35}$ This effect describes the rateacceleration of a cyclization between two reactive groups, by introducing substituents on the carbon atom that links those two groups. In the case of propargylic alcohols this implies substitution on the carbon connecting the alcohol with the alkyne moiety. The gem-dialkyl effect causes angle compression, bringing the two reactive groups closer together, also known as the "Thorpe-Ingold" effect.
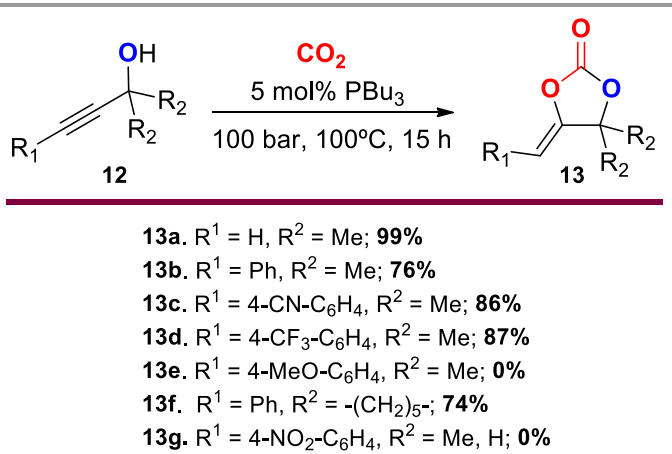

Scheme 6: Organocatalyzed carbonate formation under $\mathrm{Sc}-\mathrm{CO}_{2}$ conditions.

Concerning cyclization reactions with $\mathrm{CO}_{2}$, there are some examples where primary and secondary propargylic alcohols can be used as substrates. However, these reactions typically require high $\mathrm{CO}_{2}$ pressures to give the cyclic carbonates ${ }^{21 \mathrm{~b}, 26 \mathrm{a}}$ or are converted in the presence of amines to yield linear carbamates. ${ }^{36}$

Other organocatalysts that have been used in the same context include a $\mathrm{K}_{2} \mathrm{CO}_{3}$-crown ether, ${ }^{37}$ bicyclic guanidines, 38 alkoxide-functionalized imidazolium betaines ${ }^{39}$ and $\mathrm{N}$ heterocyclic carbenes (NHCs). ${ }^{40}$ Closely related to the latter type of organocatalysts are $\mathrm{N}$-heterocyclic olefins (NHOs), which have been shown to efficiently activate and bind $\mathrm{CO}_{2}{ }^{41}$ Scheme 7 depicts the structure of the $\mathrm{NHO}$ and subsequent formation of the adduct upon activation of $\mathrm{CO}_{2}$. An interesting property of these types of complexes is that the $\mathrm{C}$ (carboxylate)-C(NHO) bond length is significantly longer compared to its $\mathrm{NHC}-\mathrm{CO}_{2}$ analogue. This makes the NHO- $\mathrm{CO}_{2}$ adduct less stable but more suitable for catalytic turnover as facile decarboxylation takes place under milder temperature conditions $\left(60^{\circ} \mathrm{C}\right)$. These properties allow for an improved reactivity in the carboxylative cyclization of propargylic alcohols.

Two different mechanistic pathways were suggested by the authors, the first one being based on the mechanism proposed by 
Ikariya regarding related $\mathrm{NHC}$ catalysis. ${ }^{40 a}$ In this case the NHO$\mathrm{CO}_{2}$ adduct thus attacks the alkyne triple bond, followed by hydrogen transfer to form an alkoxide intermediate. This alkoxide species performs an intramolecular cyclization, which releases the cyclic carbonate product and regenerates the catalyst. Due to the different properties of the NHOs there is a second reaction pathway possible, which is outlined in scheme 8 .

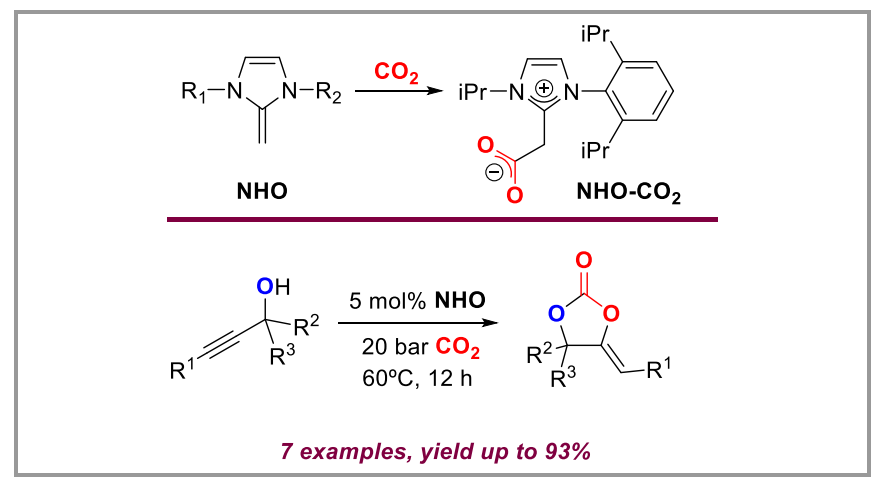

Scheme 7: Synthesis of an $\mathrm{NHO}-\mathrm{CO}_{2}$ adduct from the $\mathrm{NHO}$ and $\mathrm{CO}_{2}$ and subsequent use in the formation of $\alpha$-alkylidene cyclic carbonates.

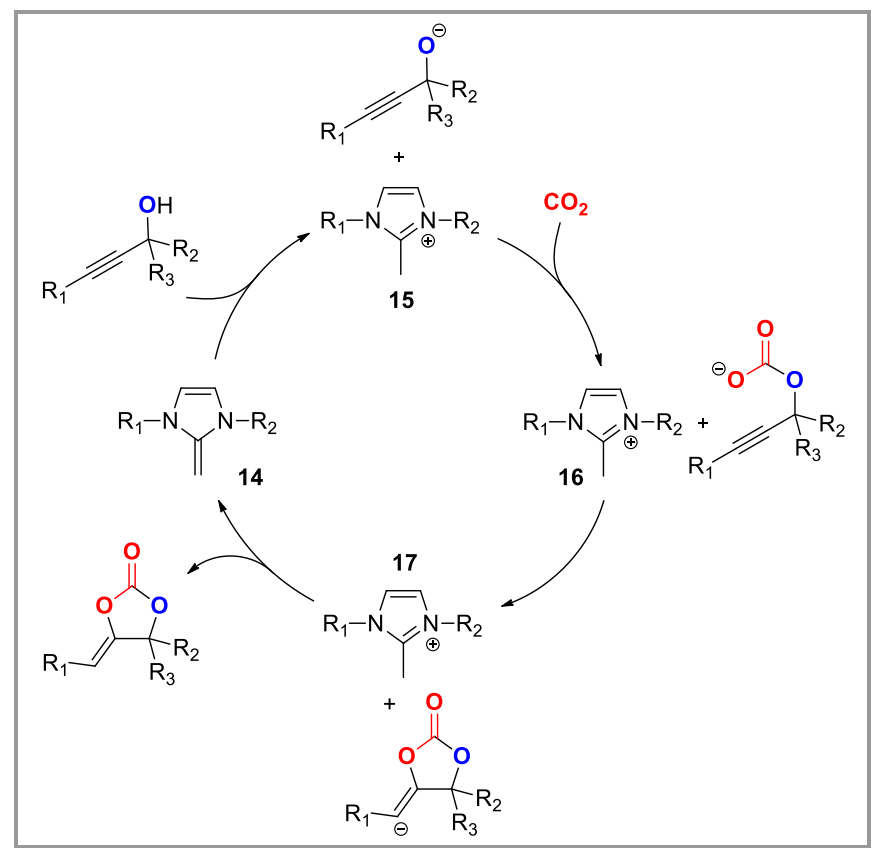

Scheme 8: Proposed reaction mechanism for the NHO-catalyzed cyclization of propargylic alcohols with $\mathrm{CO}_{2}$

In the catalytic cycle displayed in Scheme 8, the NHO (14) first deprotonates the propargylic alcohol, forming an alkoxide and an imidazolium species (15). $\mathrm{CO}_{2}$ subsequently reacts with the substrate to form a carboxylate anion (16) that attacks the alkyne moiety to give intermediate $\mathbf{1 7}$. Rapid proton exchange from the imidazolium intermediate to the carbanionic species closes the cycle with reformation of $\mathbf{1 4}$ and release of the $\alpha$ alkylidene cyclic carbonate. Kinetic isotope effect (KIE) measurements show that the second pathway (Scheme 8) makes a smaller contribution to the overall reaction compared to the manifold previously proposed for NHC catalysts. ${ }^{40 a}$

\section{Catalytic conversion of propargylic amines}

Closely related to propargylic alcohols are their $\mathrm{N}$-containing analogues, propargylic amines. Their cyclization with $\mathrm{CO}_{2}$ leads to the formation of cyclic carbamates and these 5-membered heterocyclic products are usually described as oxazolidinones. These compounds are versatile chemical products that have found application in various fields of chemistry, for instance as chiral auxiliaries, ${ }^{42}$ scaffolds for antimicrobial drugs ${ }^{43}$ or antidepressants, ${ }^{44}$ and in organic synthesis. ${ }^{45}$ In contrast to the large number of reactions based on propargylic alcohols that emerged during the end of the last century, relatively few examples have been reported for propargylic amines, probably due to the fact that the latter have more restricted accessibility. First, only the intermolecular three-component coupling had been known, combining an amine, alkyne and $\mathrm{CO}_{2}$ to form the cyclic carbamates catalyzed by either iron ${ }^{46}$ or ruthenium complexes. ${ }^{47}$ The first example of a propargylic amine being directly used in a carboxylative cyclization was reported in 1996 by the group of Costa (Scheme 9). ${ }^{48}$

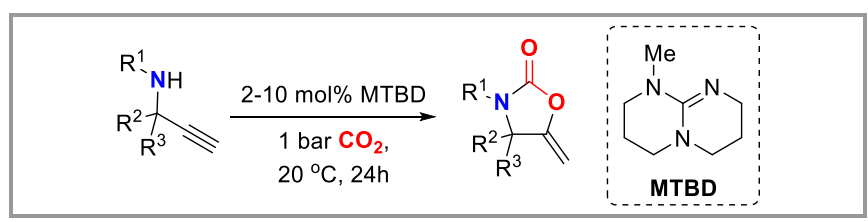

Scheme 9: Organocatalyzed incorporation of $\mathrm{CO}_{2}$ into propargylic alcohols.

They reported on the formation of 5-membered cyclic carbamates using the bicyclic guanidinium base MTBD as catalyst. Various substrates could be converted to their respective carbamate products under ambient conditions ( 1 bar $\mathrm{CO}_{2}, \mathrm{rt}$ ), although primary or secondary propargylic amines did not provide productive catalysis. When the temperature was raised to $110^{\circ} \mathrm{C}$ and the $\mathrm{CO}_{2}$ pressure to $10 \mathrm{bar}$, both targeted products could be obtained in appreciable yields in the range 60$70 \%$. This result supports the rate-enhancement caused by the gem-dialkyl effect discussed previously (see section 2.2 on propargylic alcohol conversion).

In the following years several groups reported on the synthesis of oxazolidinones and derivatives from propargylic amines using catalytic systems based on silver, ${ }^{49}$ gold, ${ }^{50}$ palladium, ${ }^{51}$ superbases ${ }^{52}$ and ionic liquids. ${ }^{53}$ Interestingly, this particular cyclization reaction with $\mathrm{CO}_{2}$ can even be performed in the absence of catalyst and solvent. Ikariya reported on the formation of cyclic carbamates from propargylic amines using supercritical $\mathrm{CO}_{2}$ both as reactant and solvent without the requirement of any further additive. ${ }^{54}$ Even more recently, a contribution towards cyclic carbamate synthesis was presented by the group of Nevado. 55

The latter example work describes a three-component tandem reaction involving the well-known cyclization step using $\mathrm{CO}_{2}$ and the propargylic amine (18) followed by an in situ Pdmediated cross-coupling of the $\alpha$-alkylidene cyclic carbonate intermediate with aryl iodides (Scheme 10). Under optimized conditions, a series of substituted oxazolidinones was prepared. Varying the nature of the aryl iodide generally led to the targeted products in high yields of up to $95 \%$ (19a-c); moderate yields were noted when electron-donating groups (EDGs) such as para- 
OMe (19d) were present in the aryl iodide reagent. Terminal alkynes could also be converted: remarkably, product 19e was isolated as the $(E)$-isomer in contrast to the $(Z)$-products which are normally obtained through coupling of internal alkynes with $\mathrm{CO}_{2}$. Furthermore, various $\mathrm{N}$-substituted propargylic amines were tested, giving good yields when the $N$-R substituents are $\mathrm{nBu}(\mathbf{1 9 f}), \mathrm{iPr}(\mathbf{1 9 g})$ or allyl. When a sterically more congested $\mathrm{tBu}$ group was present, only a moderate yield of the cyclic carbamate $19 \mathrm{~h}$ could be obtained even after a 3 day reaction time.

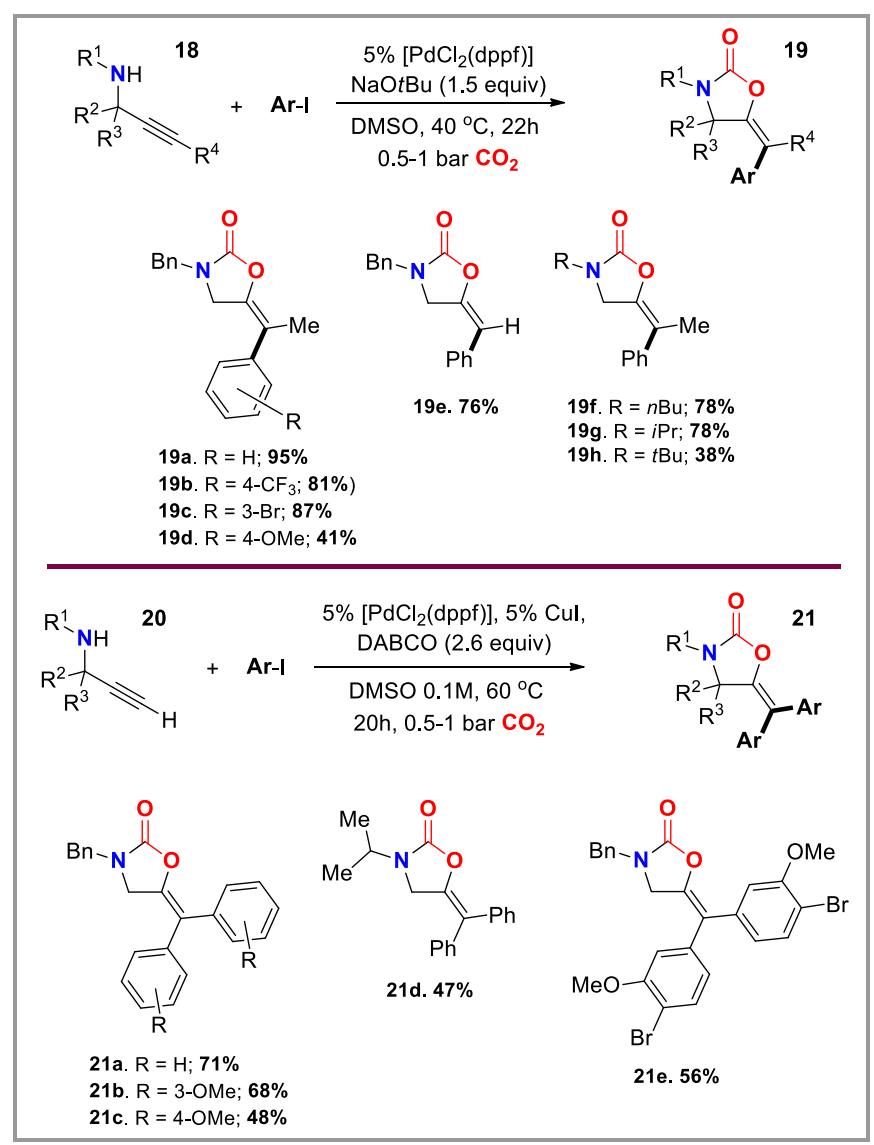

Scheme 10: Synthesis of oxazolidinones incorporating tetra-substituted exocyclic double bonds starting from internal (top) or terminal (bottom) propargylic alcohols.

In the second part of the substrate scope phase, a larger amount of aryl iodide was added ( 3 equiv.) as well as an additional catalytic amount of CuI. This smoothly led to the formation of cyclic carbamates having a tetra-substituted exocyclic double bond starting from propargylic amines with a terminal alkyne group (Scheme 10, below). Electronic variation on the aromatic ring shows a similar effect as noted within the other series of cyclic carbamate products with good yields of up to $72 \%$ when using the non-substituted aryl iodide (21a) and substrates carrying EWG substituents (21b), and poorer results for substrates having EDGs (21c; 48\% yield). The chemoselective formation of the cyclic carbamate product derived from aryl iodides equipped with additional $\mathrm{C}$ - $\mathrm{Br}$ functions was also feasible, and the latter functional groups did not participate in the cross-coupling event (cf., formation of 21e). A mechanism was tentatively proposed combining both the carboxylative cyclization and cross-coupling chemistry (Scheme 11).
Assumingly, the propargylic amine containing a terminal alkyne moiety first undergoes a Sonogashira type cross-coupling. This is suggested by the formation of an internal alkyne (22) when the reaction of $\mathbf{2 0}$ (Scheme 10, bottom) is performed in the absence of $\mathrm{CO}_{2}$.

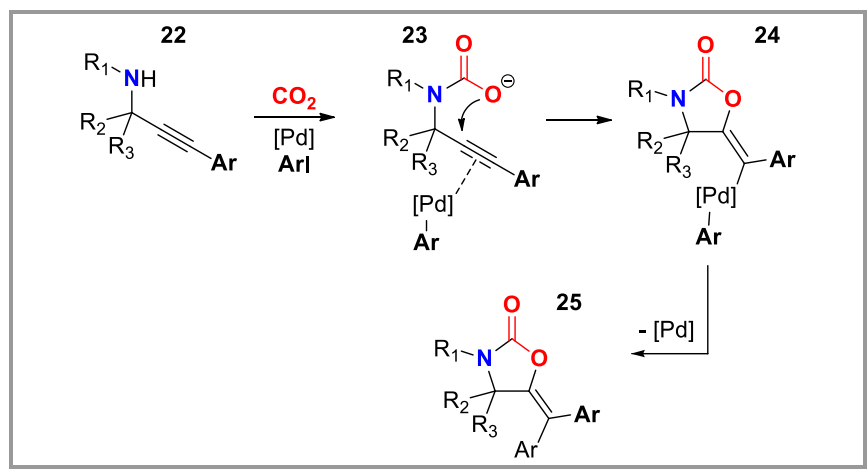

Scheme 11: Schematic representation of the carboxylative cyclization and reductive elimination steps in the $\mathrm{Pd}$-mediated three-component coupling of propargylic amines, $\mathrm{CO}_{2}$ and aryl iodides.

The second step involves the activation of $\mathrm{CO}_{2}$ by the amine unit and coordination of palladium to the alkyne triple bond to give 23. Ring closure leads to the formation of palladium-vinyl intermediate $\mathbf{2 4}$ similar to that described for the copper intermediate in Scheme 4. The difference here is that the palladium ion is not replaced by a hydrogen or iodine atom, but instead is involved in a reductive elimination process to give the final product $\mathbf{2 5}$ containing two aromatic groups on the terminal end of the double bond. Evidence for this mechanism was provided by a control experiment that showed the inability of mono-substituted products such as 19e (Scheme 10, top) to undergo an additional cross-coupling reaction to afford the tetrasubstituted olefin analogue. Overall this approach displays an efficient way to access various types of highly substituted oxazolidinones through an efficient multicomponent reaction. Although the catalytic system consisting of $\mathrm{Pd}, \mathrm{Cu}$ and a base is more complex than others reported in the literature, the wide product diversity makes it a valuable contribution to this area of $\mathrm{CO}_{2}$ conversion.

\section{4. (Homo)Allylic alcohol substrate conversions}

Rather ideal candidates for the substrate-assisted activation of $\mathrm{CO}_{2}$ are allylic alcohols. Their main advantages are their availability and broad range of substitution patterns that can be accessed. There is a broad range of allylic alcohols known that can be directly used without the need for prior modification before catalytic conversion. More complex derivatives can be easily synthesized, for instance from ketones through the use of Grignard reagents. ${ }^{56}$ However, allylic alcohols are less reactive than propargylic systems in the activation and conversion of $\mathrm{CO}_{2}$ and therefore these substrates require thus a different approach to produce effective catalytic turnover.

The first synthesis of cyclic carbonates via the coupling of allylic alcohols with $\mathrm{CO}_{2}$ was reported by Cardillo in $1981 .{ }^{57}$ This paper described the regio- and stereoselective functionalization of (homo)allylic alcohols. Key step in this process is the cyclofunctionalization of the alcohol-carbonate derivatives, 
intermediates that are formed through coupling of $\mathrm{CO}_{2}$ with allylic- or homo-allylic alcohols (Scheme 12, top).

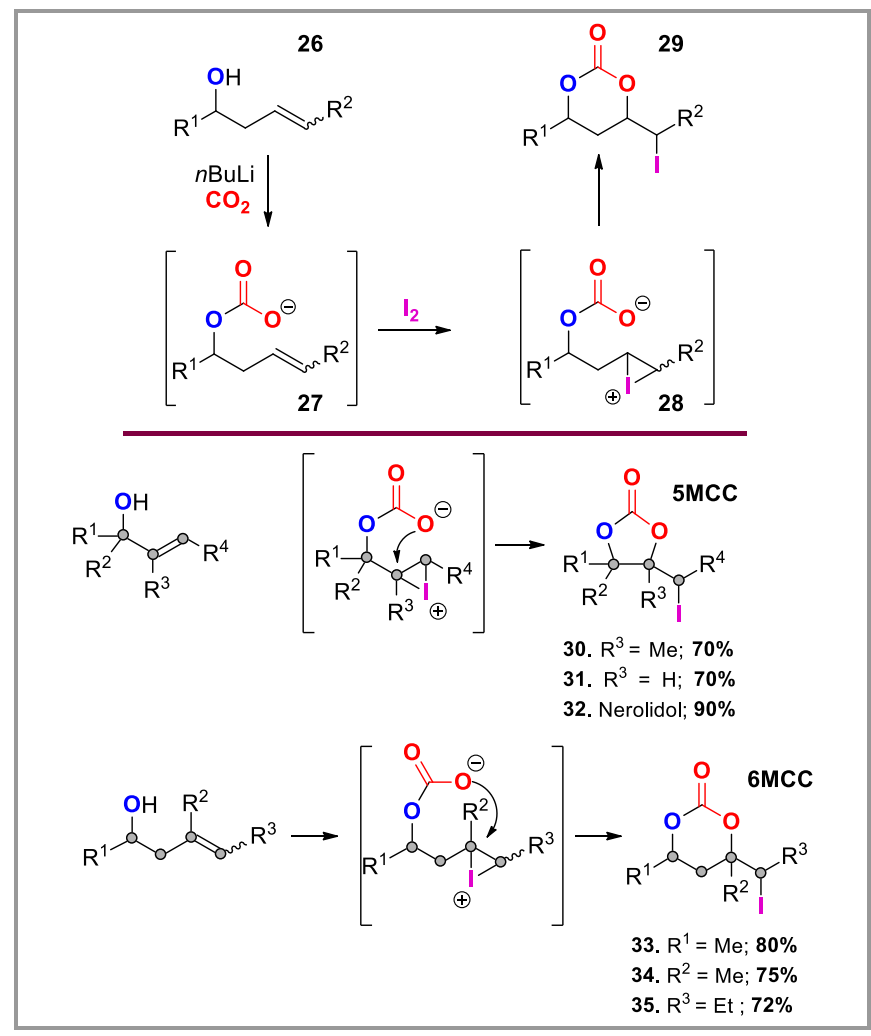

Scheme 12: Proposed mechanism towards the formation of six-membered cyclic iodocarbonates from (homo)allylic alcohols. Regioselective cyclization leading to either 5- or 6-membered cyclic carbonates is shown below with the carbon centers of the involved substrates highlighted.

A homoallylic alcohol (26) was treated with nBuLi after which $\mathrm{CO}_{2}$ was added to form the linear, open chain carbonate intermediate (27). Subsequent treatment with iodine led, assumingly, to an iodonium intermediate (28) thereby activating the double bond for intramolecular nucleophilic attack. Although the authors did not comment on the exact role of iodine in this reaction sequence, it is likely to form an iodonium species under these conditions. ${ }^{58}$ Intramolecular attack of the carbonate moiety gives the six-membered cyclic carbonate (29) and installs a synthetically useful alkyliodide group on the terminal carbon center of the carbonate side chain. The cyclization step is highly regioselective, producing exclusively 5 -membered cyclic carbonates (5MCCs) from allylic alcohols and six-membered (6MCCs) derivatives from the respective homo-allylic alcohols (Scheme 12; below). Several iodocarbonates can be easily prepared by this methodology. Interestingly, the best carbonate yield was obtained when nerolidol was used as substrate, a natural product containing three non-conjugated double bonds. Only the double bond in the allylic position from the alcohol reacts, giving the corresponding 5MCC in $90 \%$ yield (32). The main disadvantage of this method is, however, the need for a strong and air-sensitive base (nBuLi) for the reaction to proceed. This limits the scope of the reaction as many functional groups are not compatible under these conditions.

Nearly thirty years after the initial work from Cardillo was reported, ${ }^{57}$ Minakata and co-workers presented an elegant variation of this protocol towards the formation of iodofunctionalized cyclic carbonates. ${ }^{23}$ Instead of utilizing a strong base to force the formation of a carbonate intermediate, they made use of the reaction of $\mathrm{CO}_{2}$ with alcohols that results in the formation of an unstable carbonic acid monoester (Scheme 13, 37). The formation of this carbonic acid monoester is thermodynamically highly disfavored. However, the carbonate intermediate can be trapped by using a reactive iodonium source, i.e. tert-butyl hypoiodite (tBuOI). ${ }^{59}$ Subsequent ring-closure forms the cyclic carbonate (39) and effectively displaces the equilibrium towards the targeted product. Whereas the reaction of molecular iodine with olefins usually proceeds through an iodonium intermediate, a different mechanism is likely operative when using tBuOI. Formation of an iodonium species with tBuOI has been reported, though specifically for substrates lacking a hydroxyl group. ${ }^{60}$ It was proposed that the iodine atom from tBuOI initially replaces the proton of the alcohol group to generate a reactive intermediate $(\mathbf{3 8})$ that can cyclize to give the cyclic carbonate (39). A similar result was obtained for amides, which can be deprotonated by the hypoiodite reagent leading to the formation of oxazolines. ${ }^{61}$ This different reaction pathway can be explained by the potential of tBuOI to readily form radicals. Whereas molecular iodine can lead to radical pathways under the influence of light ${ }^{62}$ or radical initiators, ${ }^{63}$ tBuOI does not require any external stimulus.

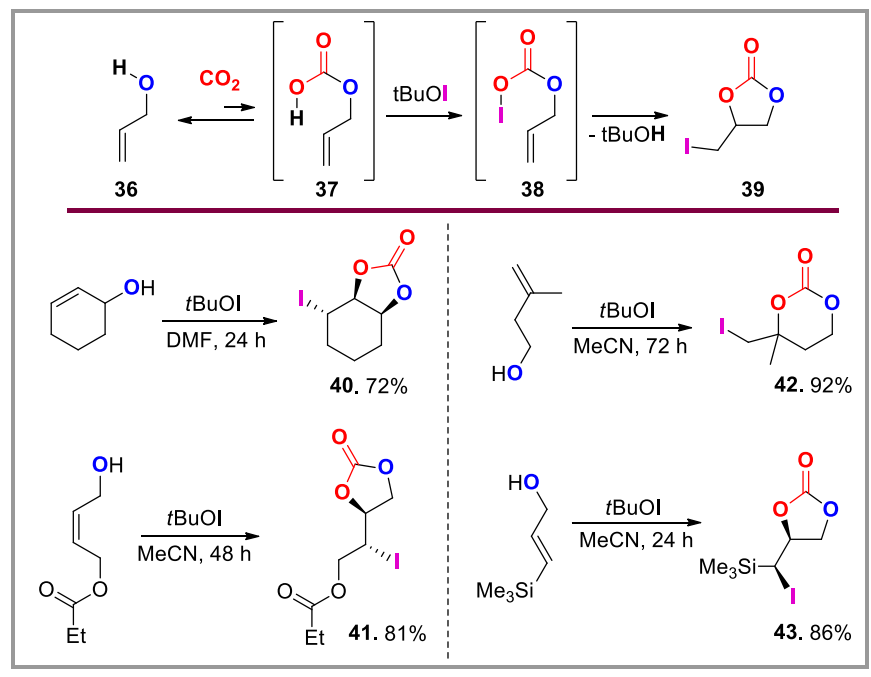

Scheme 13: Proposed mechanism of trapping of a carbonic acid monoester with tert-butyl hypoiodite ( $t \mathrm{BuOl})$. Below the stereo- and regio-selective formation of cyclic carbonates with $\mathrm{tBuOI}$ (selected examples) under mild conditions ( 1 bar, $-20 \%$ C)

This approach can be applied to the conversion of a wide variety of allylic and homo-allylic alcohols leading to the formation of 5MCCs and 6MCCs, respectively (Scheme 13; below). The products are generally obtained in high yields under very mild conditions ( 1 bar, $-20^{\circ} \mathrm{C}$ ) with reaction times ranging from 3 to $72 \mathrm{~h}$. This methodology can also be applied to the conversion of propargylic alcohols forming 5MCCs with an exocyclic double bond (see section 2).

An enantioselective approach towards the formation of cyclic iodocarbonates was reported by Johnston. ${ }^{64}$ Their work centers on the use of an organocatalytic system employing dual Brønsted acid/base catalysis in combination with $\mathrm{N}$-iodosuccinimide 
(NIS). The mechanism for this reaction is similar to that described above, with the iodine forming an iodonium intermediate that activates the alkene for a nucleophilic attack by the carbonate species. The difference lies in the role of the organo-catalyst abbreviated as StilbPBAM (Scheme 14, 46) that serves as both a Brønsted base to stabilize the carbonate moiety and creates a chiral environment during the cyclization step.

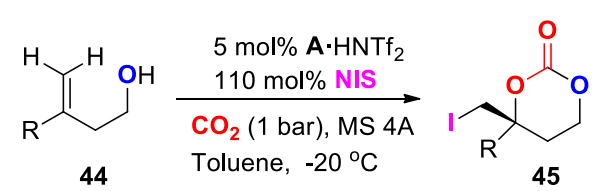

45a. $\mathrm{R}=\mathrm{p}-\mathrm{MeO}-\mathrm{C}_{6} \mathrm{H}_{4} ; \mathbf{9 6 \%}, \mathbf{9 1 \%}$ ee

45b. $\mathrm{R}=\mathrm{m}-\mathrm{MeO}-\mathrm{C}_{6} \mathrm{H}_{4} ; \mathbf{9 7 \%}, \mathbf{9 0 \%}$ ee

45c. $\mathrm{R}=0-\mathrm{MeO}-\mathrm{C}_{6} \mathrm{H}_{4} ; 0 \%$

45d. $\mathrm{R}=\mathrm{p}-\mathrm{Br}-\mathrm{C}_{6} \mathrm{H}_{4} ; \mathbf{6 5 \%}, \mathbf{9 0 \%}$ ee

45e. $\mathrm{R}=\mathrm{m}-\mathrm{F}-\mathrm{C}_{6} \mathrm{H}_{4} ; \mathbf{4 0 \%}, \mathbf{8 9 \%}$ ee

45f. $\mathrm{R}=\mathrm{Me} ; \mathbf{7 2} \%, 68 \%$ ee

45g. $R=C y ; 76 \%, 74 \%$ ee

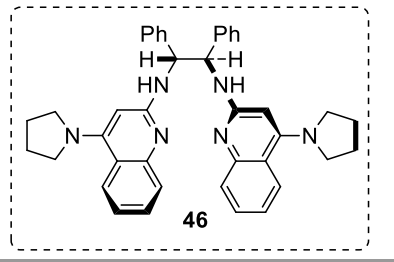

Scheme 14: Enantioselective coupling of homo-allylic alcohols and $\mathrm{CO}_{2}$.

Initial screening showed that the best yields were obtained with the chiral PBAM catalyst over several conventional aminebases and HBDs such as DMAP, DBU and TBD. Addition of a Brønsted acid $\left(\mathrm{HNTf}_{2}\right)$ increases both the yield and $e e$ of the product, which is ascribed to the occurrence of a hydrogenbonding network during catalysis. Under the optimized conditions a range of 19 substrates could be converted to their chiral cyclic carbonate products (Scheme 14; selected examples). Para- and meta-substitution on the aromatic ring of the homoallylic alcohol substrate gave the products in excellent yield of up to $96 \%$ and $e e$ 's of up to $91 \%$ (45a-b). Ortho-substituted aryl groups were not tolerated as no product formation was observed even after long (>96 h) reaction times (45c). The enantioselectivity remained fairly constant around $90 \%$ upon changing substituents, though with a drop in yield when using halogenated aryl-substituted homo-allylic alcohols (45d-e). Even challenging substrates bearing aliphatic substituents showed fairly good results both in terms of yield and enantioselectivity (45f-g).

The general development of the coupling reaction between $\mathrm{CO}_{2}$ and (homo)-allylic alcohols has provided access to a variety of synthetically interesting organic molecules. However, due to the rather low reactivity of olefinic double bonds, a stoichiometric amount of iodine is typically required for the reaction to proceed. As a consequence, an iodide is incorporated in the product leading to the formation of cyclic iodocarbonates in all cases. This is not necessarily a disadvantage, as the iodine moiety opens up possibilities for post-modification reactions as shown in Scheme 15. Useful transformations of the cyclic iodocarbonate include the partial and full reduction leading to the (chiral) 6MCC (47) and 1,3-diol (48). Basic hydrolysis of the carbonate gives the epoxide compound 49 through initial iodohydrin formation followed by cyclization. It is important to note here that the initial $e e$ of the cyclic iodocarbonate (91\%) is retained in carbonate derived compounds 47-49. Other possible modifications of this type of cyclic iodocarbonates containing a primary alkyl iodide have been investigated including nucleophilic substitutions and cross-coupling reactions. ${ }^{65}$

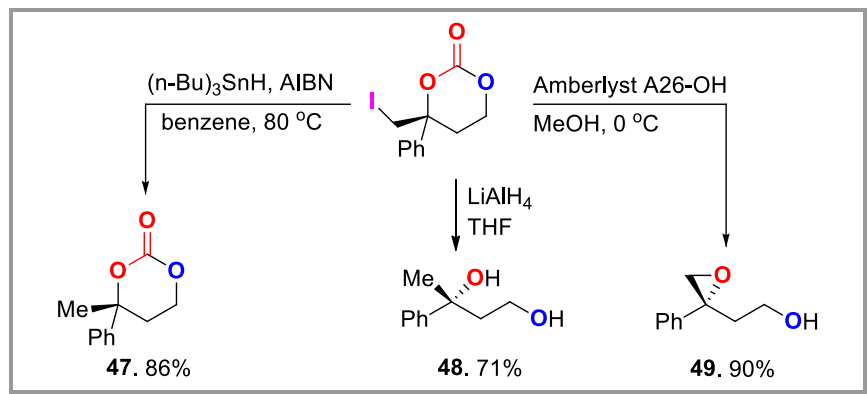

Scheme 15: Transformation of cyclic iodocarbonate structures into various useful molecules.

\section{Transformation of allylic amines}

Similar to the carboxylative cyclization of allylic alcohols is the formation of cyclic carbamates from allylic amines and $\mathrm{CO}_{2}$. Early investigations described the three-component coupling reaction of an amine, $\mathrm{CO}_{2}$ and an olefinic substrate. ${ }^{66}$ Allylic amines were used for the first time in a related transformation utilizing a carbonate anion, ${ }^{67}$ whereas the first example using carbon dioxide was published in 1987 by the group of Toda. ${ }^{68}$ In the latter example the formation of 5- and 6-membered cyclic carbamates (oxazolidinones and oxazinanones) from allylic- and homo-allylic amines, respectively, was reported. This approach follows the same mechanistic pathway as described for the conversion of allylic alcohols with $\mathrm{CO}_{2}$ and iodine (section 4). A minor drawback of this approach is the need for longer reaction times and the requirement of a base additive $\left(\mathrm{Cs}_{2} \mathrm{CO}_{3}\right)$ to achieve high yields. Improved versions of the coupling of allylic amines with $\mathrm{CO}_{2}$ have been reported by Muñoz, ${ }^{69}$ (using a guanidine based catalyst) and later on by Minakata. ${ }^{70}$ In the latter case an organic additive is used (tBuOI) thereby excluding the need for a metal or base to catalyze this reaction.

The (homo)allylic amines are transformed into their respective products following the same mechanistic steps as depicted in Scheme 13. A variety of cyclic carbamates can be obtained through this method with yields ranging from $54-94 \%$. An interesting application for this method was found in the synthesis of 3-amino-5-morpholinomethyl-2-oxazolidinone (AMOZ, Scheme 16). AMOZ is a metabolite of several larger drug molecules (for instance of furaltadone) ${ }^{71}$ which has been used as an antibiotic. ${ }^{72} \mathrm{~A}$ simple three-step process transforms allyl amine (50) into AMOZ (53), through initial coupling with $\mathrm{CO}_{2}$ in the presence of tBuOI to form the iodinated oxazolidinone $\mathbf{5 1}$. The alkyl iodide can then be converted by simple nucleophilic substitution chemistry to install the morpholine unit (52). A hydrazide is formed in the last step, giving the final product AMOZ (53). 


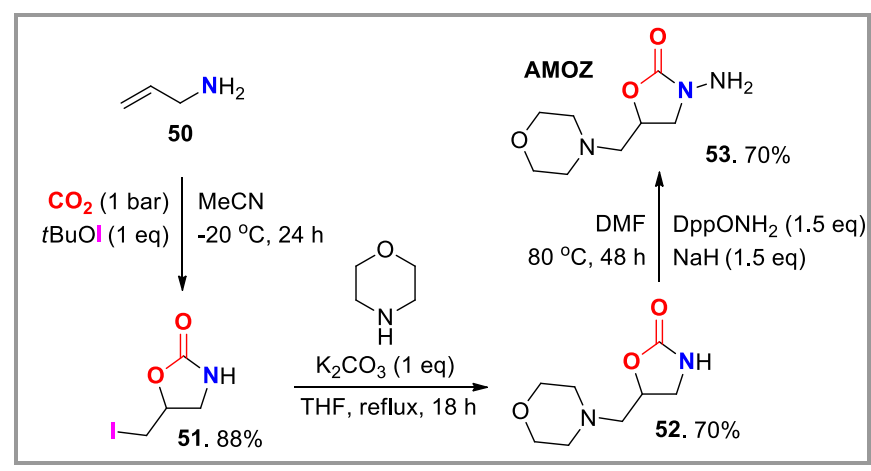

Scheme 16: Three-step synthesis of the AMOZ drug precursor.

Other examples of cyclic carbamate formations from allylic alcohols include a palladium catalyzed $\mathrm{CO}_{2}$ "recycling" reaction reported by Yoshida. ${ }^{73}$ The substrates are allylic amines bearing a methyl carbonate group in the allylic position. The first step in the proposed mechanism involves a Pd-mediated decarboxylation with subsequent formation of a $\pi$-allyl-Pd complex. Carbon dioxide is concomitantly trapped by DBU (a bicyclic base) and transferred to the amine group. Intramolecular nucleophilic attack of the newly formed carbamate species results then into the final oxazolidinone product. An effective alternative approach towards the carboxylative cyclization of allyl amines $\mathbf{5 4}$ (Scheme 17) was recently developed by the group of Della Ca'. ${ }^{74}$ They reported on the synthesis of oxazolidinones $\mathbf{5 5}$ from allyl amines in the absence of a metal or base catalyst. However, the presence of a strong EWG attached to the double bond was required to facilitate the cyclization step by the initially formed carbamate anion. An EWG such as an ester can be used to stabilize the negative charge that forms after intramolecular attack followed by rapid proton transfer to give the final product. Initially, the reaction was performed under 45-60 bar of $\mathrm{CO}_{2}$ at $90^{\circ} \mathrm{C}$ to obtain the benchmark product in high yield; however, other substrates gave much poorer results in terms of conversion/yields. This problem could be eventually overcome by performing the reactions in $\mathrm{scCO}_{2}$ thereby significantly improving the yields in most cases.

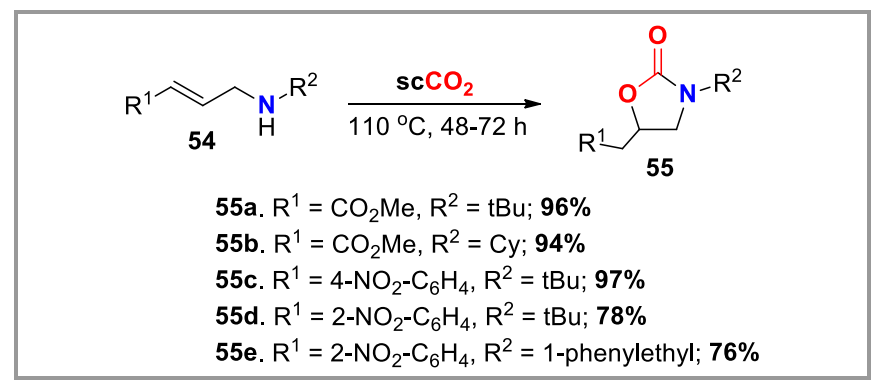

Scheme 17: Synthesis of oxazolidinone 55 derivatives from allyl amines 54 in $\mathrm{SCCO}_{2}$.

Substrates bearing an ester group could be efficiently converted producing the carbamates in excellent yields (55a-b). No product formation was observed when $\mathrm{R}^{1}$ is hydrogen, alkyl or phenyl. However, when an additional nitro group was present on the aryl ring, the oxazolidinone product was obtained in high yield (cf., formation of $\mathbf{5 5 c - e}$ ). Note that under non-supercritical conditions, only $51 \%$ yield of product $\mathbf{5 5 c}$ was obtained and less than $20 \%$ in the case of $\mathbf{5 5} \mathbf{d}$ and $\mathbf{5 5 e}$. Thus, this method provides a very simple way to form cyclic carbamates from allylic amines in good yields without the need for any additives. However, this approach is applicable to a smaller range of substrates, thereby limiting to some extent the synthetic potential of this protocol.

\section{Epoxy alcohols/amines as substrates}

The main difference between epoxy alcohols/amines and the previously described allylic and propargylic systems is that there are two different ways for the substrate to react with $\mathrm{CO}_{2}$. Conversion of epoxides to cyclic carbonates by binary catalytic systems has been well documented over the past few decades. ${ }^{75}$ Binary catalytic systems typically consist of a Lewis or Brønsted acid (a metal complex or hydrogen bond donor (HBD)) and a nucleophilic additive (Scheme 18; left). The Lewis acid activates the epoxide through initial coordination followed by ringopening by the external nucleophile to give a metal-alkoxide species, followed by insertion of $\mathrm{CO}_{2}$ into the $\mathrm{M}-\mathrm{O}$ bond and subsequent ring-closure producing the cyclic carbonate product. In the case of epoxy alcohols or amines, a carbonate anion can be formed that acts an internal nucleophile. This allows for a substrate-assisted pathway leading to a different product (Scheme 18; right) which is discussed here in more detail. ${ }^{76}$

Direct

Scheme 18: Two different mechanistic manifolds for the reaction between epoxy alcohols/amines and $\mathrm{CO}_{2}$.

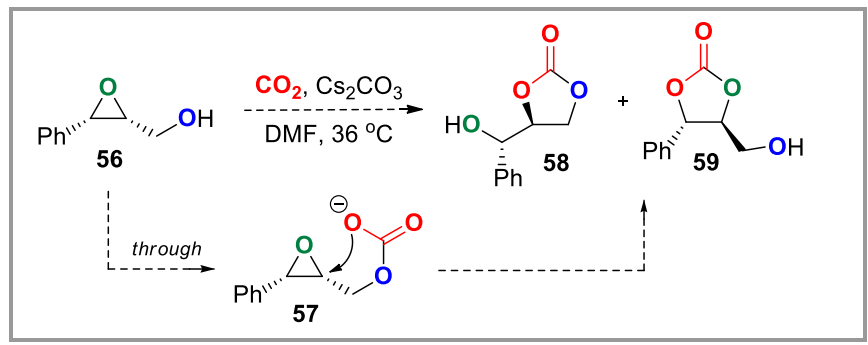

Scheme 19: Synthesis of hydroxyl-methyl carbonates from epoxy alcohols and $\mathrm{CO}_{2}$ under basic conditions leading to a mixture of 58 and 59 .

An intermolecular variation on this reaction was reported by Inoue in 1986, employing an aluminum porphyrin complex to catalyze the coupling of an amine, $\mathrm{CO}_{2}$ and an epoxide. ${ }^{77} \mathrm{~A}$ more recent contribution relevant to these conversions came from the group of Deng who reported the formation of linear hydroxy carbamates catalyzed by a heterogeneous $\mathrm{Au} / \mathrm{Fe}_{2} \mathrm{O}_{3}$ catalyst system. ${ }^{78}$ The intramolecular version was first described in $1987,{ }^{79}$ although the cyclic carbonate product was not obtained in this case. One year later Myers et al. reported on the successful 
carboxylative cyclization utilizing epoxy alcohols to form cyclic carbonates $^{80}$ (Scheme 19) mediated by cesium carbonate.

The mechanism of the reaction proceeds in a similar way as that described for the allylic and propargylic systems. Carbon dioxide is activated by the hydroxyl group of $\mathbf{5 6}$ and the newly formed carbonate anion (57) performs an intramolecular attack on the epoxide followed by proton transfer to furnish the cyclic carbonate product (58). In addition, the authors observed the formation of $\mathbf{5 9}$ with a final product distribution of 1:3 with $\mathbf{5 9}$ being the major product. In 2005, the first example of an epoxy amine $/ \mathrm{CO}_{2}$ coupling was reported by Plettner, ${ }^{81}$ who observed the formation of a hydroxyl substituted oxazolidinone instead of the cyclic carbonate product.

A large step forward in substrate-controlled cyclic carbonate formation from epoxy alcohols and amines was demonstrated very recently by Kleij et al. ${ }^{76}$ The authors showed that two different products can be formed from a single substrate (i.e., product divergence) and catalyst depending on the reaction conditions that are used (Scheme 20; $\mathbf{A l}^{\mathbf{t B u}}$ as catalyst). Epoxy alcohols bearing an alcohol group in the $\beta$-position could be converted into their respective cyclic carbonate products to provide unusual and challenging substitution patterns that are difficult to synthesize via conventional epoxide $/ \mathrm{CO}_{2}$ coupling reactions.

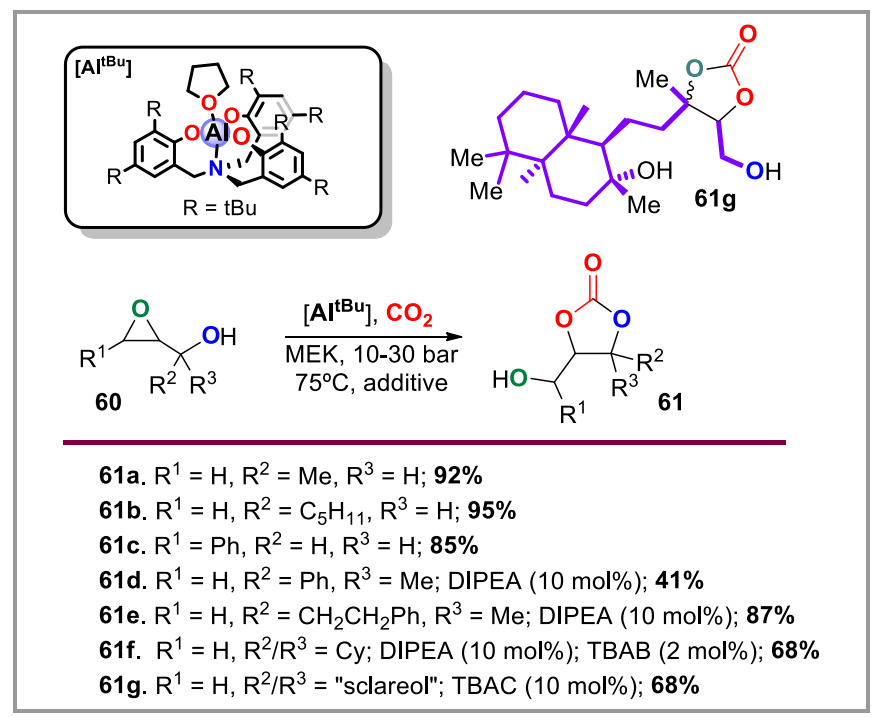

Scheme 20: Synthesis of highly substituted cyclic carbonates through a substrate-controlled $\mathrm{CO}_{2}$ activation process. DIPEA = diisopropylethylamine, $\mathrm{TBAB}=$ tetrabutylammonium bromide; TBAC is the chloride variant of TBAB.

Both terminal and internal epoxy alcohols (60) could be efficiently converted leading to the formation of mono- and disubstituted cyclic carbonates in excellent yields of up to $95 \%$ (cf., formation of 61a-c). Sterically crowded tertiary alcohols required higher reaction pressures. In addition, a base (DIPEA) was added for some substrates to mediate the deprotonation of the alcohol group and favor the formation of the linear carbonate intermediate; in these cases the conversions led to the formation of elusive tri-substituted carbonates (cf., formation of compounds 61d-e). Other challenging substrates required the addition of a small amount of nucleophile to increase overall kinetics. The chemoselectivity, however, is slightly compromised in those cases due to two competing pathways leading to different carbonate products (Schemes 18 and 19). Nonetheless, products $\mathbf{6 1 f}$ and $\mathbf{6 1 g}$ were obtained in good yields under the optimized conditions. A second part of the substrate scope focused on the conversion of epoxy amines (62) that form oxazolidinones highly selectively in the presence of $\mathrm{CO}_{2}$ and the Al based catalyst (Scheme 21).

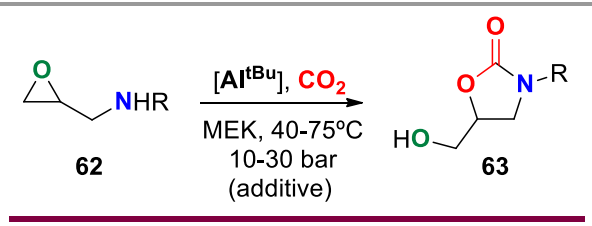

63a. $\mathrm{R}=\mathrm{Bn} ; \mathbf{9 4 \%}$

63b. $R=\mathrm{tBu} ; 81 \%$

63c. $R=$ Ts; DIPEA (10 mol\%); $65 \%$

63d. $\mathrm{R}=3-\mathrm{Me}$-aryl; TBAB (2 mol\%); $74 \%$ Toloxatone

Scheme 21: Use of epoxy amines and their conversion into cyclic carbamates or oxazolidinones. Ts = tosyl, DIPEA = diisopropylethylamine, $\mathrm{TBAB}=$ tetrabutylammonium bromide.

Alkyl substitutions on the epoxy amine result in relatively fast reactions under mild temperature conditions (30-40을 $\mathrm{cf}$. formation of $\mathbf{6 3 a - b}$ ). Under the same conditions, no reaction was observed for the epoxy amines with an $\mathrm{N}$-tosyl or $\mathrm{N}$-aryl fragment. A base (DIPEA) was thus necessary to facilitate deprotonation of the epoxy amine, thereby favoring the formation of a linear carbamate intermediate and product formation (compound 63c). An aniline based epoxy amine can be converted with complete selectivity for the carbamate product when using DIPEA, though the reaction is relatively slow in this case. Addition of a small amount of nucleophile significantly speeds up the process, with only a minor loss in chemoselectivity (cf., 63d). Interestingly, the oxazolidinone product formed here is known as Toloxatone, a drug molecule that is used as an antidepressant. ${ }^{44}$

\section{Hydroxy oxetanes and azetidines scaffolds}

Larger ring-size cyclic ethers such as oxetanes also provide interesting substrates for $\mathrm{CO}_{2}$ activation; azetidines are the nitrogen-containing analogues. When substituted with hydroxyl groups, these substrates provide opportunities for the activation of $\mathrm{CO}_{2}$ in a similar way as described for epoxy alcohols (section 6). A three-component coupling reaction between an amine, $\mathrm{CO}_{2}$ and an oxetane has been described in 1999 by Yoshida et al ${ }^{82}$ showing the potential of amines to activate $\mathrm{CO}_{2}$ in situ. Various linear hydroxyalkyl carbamates were synthesized in the absence of a catalyst though under relatively high temperature and pressure conditions $\left(120^{\circ} \mathrm{C}\right.$ and 40 bar). An intramolecular variant was reported by the group of Murakami, describing the cyclization of a hydroxyl-azetidine (azetidinol) with $\mathrm{CO}_{2}{ }^{83}$ The initial synthesis of the azetidinol is achieved through a solar light driven photolysis of $\alpha$-amido ketones. ${ }^{84}$ Subsequent coupling of the azetidinol and $\mathrm{CO}_{2}$ is proposed to take place according to the mechanism depicted in Scheme 22.

The first step is the deprotonation of $\mathbf{6 4}$ by cesium carbonate to give the alkoxide species 65 . Reaction with $\mathrm{CO}_{2}$ gives the carbonate anion intermediate $\mathbf{6 6}$, which enables ring-opening of the azetidine through an intramolecular nucleophilic attack 
leading to 67. Final protonation yields the cyclic carbonate product 68. Both the photolysis and carboxylative cyclization can be combined to make this reaction an efficient one-pot process. The scope of the one-pot reaction was investigated by changing the substitution on the aryl and amine group (Scheme 22; below). First the influence of the aryl substitution was tested, leading to moderate to high yields (compounds 70a-c). Also different substituted tosyl groups were investigated, which all afforded the cyclic carbonate products in good yields (compounds 70d-f). Overall this method provides an efficient and simple way to synthesize amino-substituted cyclic carbonates though still with a limited functional group diversity.
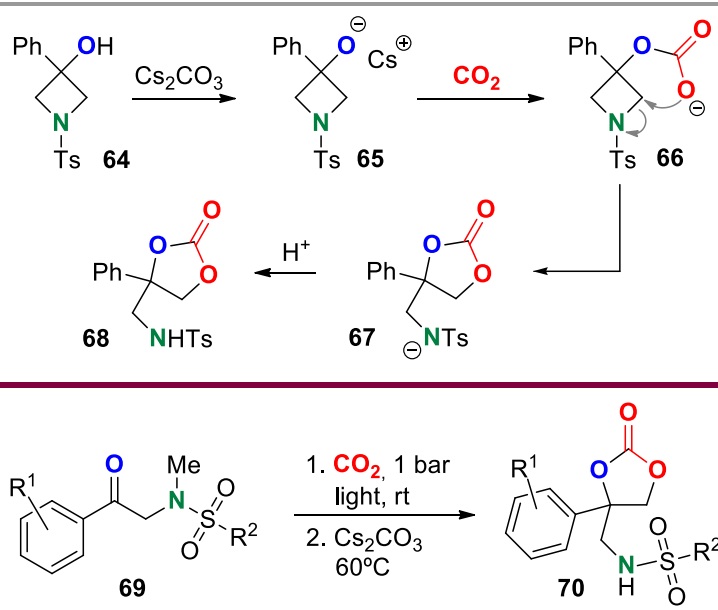

70a. $\mathrm{R}^{1}=4-\mathrm{MeO}, \mathrm{R}^{2}=4-\mathrm{Me}-\mathrm{C}_{6} \mathrm{H}_{4} ; 80 \%$

70b. $\mathrm{R}^{1}=4-\mathrm{CF}_{3}, \mathrm{R}^{2}=4-\mathrm{Me}-\mathrm{C}_{6} \mathrm{H}_{4} ; 57 \%$

70c. $\mathrm{R}^{1}=4-\mathrm{Br}, \mathrm{R}^{2}=4-\mathrm{Me}-\mathrm{C}_{6} \mathrm{H}_{4} ; 85 \%$

70d. $\mathrm{R}^{1}=\mathrm{H}, \mathrm{R}^{2}=4-\mathrm{MeO}-\mathrm{C}_{6} \mathrm{H}_{4} ; 87 \%$

70e. $\mathrm{R}^{1}=\mathrm{H}, \mathrm{R}^{2}=4-\mathrm{CF}_{3}-\mathrm{C}_{6} \mathrm{H}_{4} ; 85 \%$

70f. $R^{1}=H, R^{2}=2-P y ; 87 \%$

Scheme 22: Proposed mechanism for the coupling of an azetidinol with $\mathrm{CO}_{2}$ top) and the investigated substrate scope (below).

The reaction of $\mathrm{CO}_{2}$ with hydroxy- or amino-oxetanes was recently described by the group of Kleij. A series of oxetanes having a hydroxy or amine substituent in the 3-position were smoothly converted to cyclic carbonates and carbamates respectively. (Scheme 23). ${ }^{85}$ Cyclic carbonates derived from 3hydroxy-oxetanes were obtained under very mild conditions with temperatures as low as $50^{\circ} \mathrm{C}$ depending on the substitution (cf., 71 and 74). In a similar fashion, 3-amino-oxetanes react with $\mathrm{CO}_{2}$ to give the 5- and 6-membered cyclic carbamate products (products 72 and 73). Direct $\mathrm{CO}_{2}$ insertion into the oxetane to give the 6-membered cyclic carbonate was not observed in neither of these cases. The latter type of reaction typically requires higher onset temperatures of $>60^{\circ} \mathrm{C}$, while the substrates displayed in Scheme 23 react readily at temperatures between $25-50^{\circ} \mathrm{C}$. The proposed mechanism of the reaction follows the manifold reported in Scheme 22. Carbon dioxide is activated by the pendant alcohol group of the oxetane, to generate an internal nucleophile being a linear carbonate or carbamate anion. Intramolecular nucleophilic attack enables ring-opening of the oxetane to give the cyclic carbonate or carbamate product. In general, this reaction does not require an external nucleophile such as TBAB, but it was found that this (in some cases) may speed up the reaction without compromising the chemoselectivity.

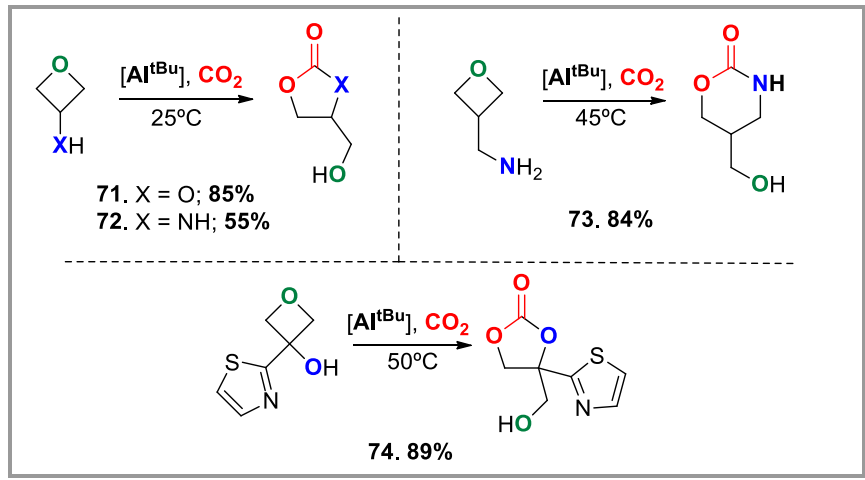

Scheme 23: Exemplary conversions of hydroxy- and amino-functionalized oxetanes into cyclic carbonates and carbamates.

\section{Conversion of other substrates}

Various other types of scaffolds can be considered for substrate-assisted activation of carbon dioxide including diols (see introduction) or halohydrins. The three-component coupling of an amine/alcohol with $\mathrm{CO}_{2}$ and a halide can be used to obtain linear carbamates ${ }^{86}$ and carbonates, ${ }^{87}$ respectively. Combination of a diol and a dihalide in the presence of $\mathrm{CO}_{2}$ leads to polycarbonates. ${ }^{88}$ Even cyclic carbonates can be formed through this approach when the alcohol and halide functionalities are both present in the same substrate. ${ }^{89}$ For instance, the group of Zhang reported the formation of both 5and 6-membered cyclic carbonates from 1,2- and 1,3-haloalcohols catalyzed by cesium carbonate. $89 \mathrm{~b}$

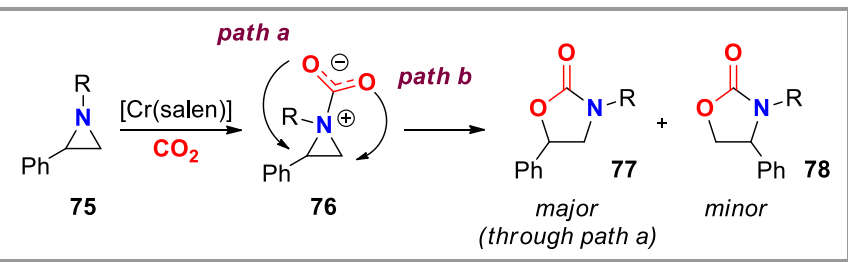

Scheme 24: Proposed mechanism for the $\mathrm{Cr}$ (salen) catalyzed formation of 4 and 5-substituted oxazolidinones.

Aziridines also allow for activation of $\mathrm{CO}_{2}$ leading to the formation of oxazolidinones. Synthesis of the latter via aziridine $/ \mathrm{CO}_{2}$ coupling was discovered in 1976 by the group of Ikeda, who reported an iodine mediated synthesis of oxazolidinones. ${ }^{90}$ Subsequent reports on this topic include catalytic systems based on ionic liquids, ${ }^{91}$ iron, ${ }^{92}$ chromium ${ }^{93}$ and organocatalysts. ${ }^{94}$ Pinhas et al. showed that the reaction can even be performed in the absence of solvent and catalyst. 95 An interesting contribution to this area was presented by Baik, Nguyen and coworkers who reported on the synthesis of 5substituted oxazolidinones from aziridines. ${ }^{93}$ Normally the formation of the 4-substituted product is favored, as ringopening occurs on the least substituted position of the aziridine ring. ${ }^{94 a, 95}$ In this specific case, however, the regio-selectivity is not dominated by sterics but by electronic effects. Scheme 24 displays the proposed mechanism leading to the formation of both the 4- and 5-substituted isomers, respectively. 
Instead of initial ring-opening of the aziridine moiety by the $\mathrm{Cr}$ (salen) complex, the metal here serves to activate $\mathrm{CO}_{2}$. Nucleophilic attack of the aziridine (75) on $\mathrm{CO}_{2}$ leads to the formation of a carbamate intermediate (76). The newly formed carbamate anion acts as an internal nucleophile that can open the aziridine via two possible pathways. Attack on the substituted carbon (path a) leads to the major (5-substituted) oxazolidinone $\mathbf{7 7}$ and path $b$ gives rise to formation of the minor (4-substituted) product 78. It was suggested that the reaction proceeds through elongation of one of the $\mathrm{C}-\mathrm{N}$ bonds in the aziridine prior to intramolecular nucleophilic ring-opening of the aziridine. The more substituted carbon center bearing the phenyl group has more cationic character leading to elongation of the corresponding $\mathrm{C}-\mathrm{N}$ bond. As a result, the ring-opening preferentially occurs at the more substituted carbon as was supported by DFT calculations.

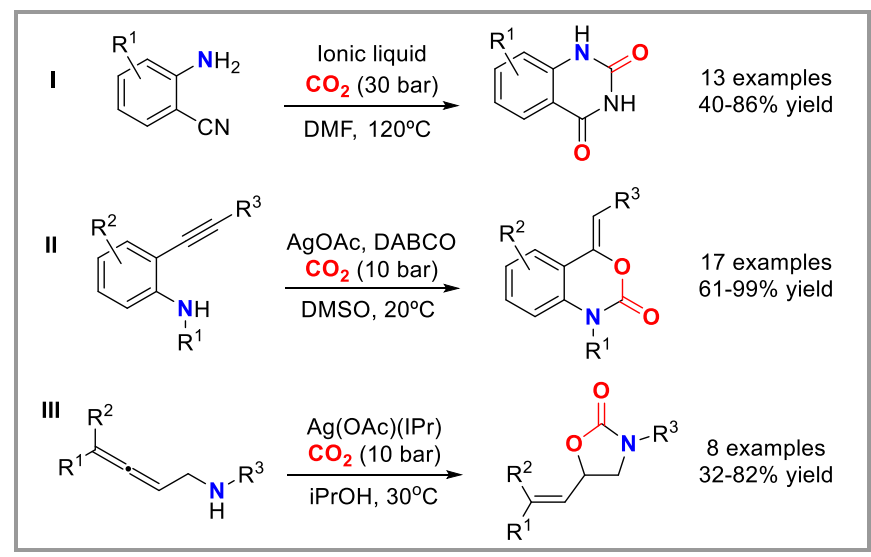

Scheme 25: Substrate-assisted activation of $\mathrm{CO}_{2}$ with 2-aminobenzonitriles (I), o-alkynylanilines (II) or allenyl methylamines (III) leading to various heterocyclic products.

In addition, a Hammet-correlation study was performed to investigate the effect of electronic substitution at the phenyl ring. Electron-donating substituents were found to give higher regioselectivity in line with their increased ability to stabilize the carbocation intermediate. When an aryl group was used having a para-methoxy substituent, the selectivity increased to $80: 1$ (versus 40:1 for simple phenyl) in favor of the 5-substituted oxazolidinone. Other possible $\mathrm{N}$-containing substrates include (aromatic) amines with additional nitrile, alkyne or allene functionalities that may give rise to various types of cyclization products after reaction with $\mathrm{CO}_{2}$ (Scheme 25). ${ }^{96-98}$

\section{Summary and outlook}

The substrate-assisted activation of $\mathrm{CO}_{2}$ has become a powerful strategy to convert a waste molecule into value-added organic matter. Various scaffolds have been shown to produce heterocyclic structures with interesting (post)synthetic potential. Typical scaffolds that provide new reactivity patterns include propargylic compounds, (homo)allylic compounds, epoxy alcohols/amines and other cyclic ethers such as oxetanes: it can be anticipated that new combinations of $\mathrm{CO}_{2}$ activating groups and functional groups that assist cyclization or any other type of irreversible transformation will be developed in the near future providing new synthons for pharmaceutical development programs and $\mathrm{CO}_{2}$ based polymers. This review clearly demonstrates the significant progress that has been made in the area of substrate-controlled $\mathrm{CO}_{2}$ conversion in terms of catalyst activity and development of alternative chemo-selectivity allowing for $\mathrm{CO}_{2}$ conversions at lower temperature and pressure, and diversification of the products that can be derived from this carbon renewable. However, there is still room for improvement for many of the discussed substrate classes, especially in terms of product scope and functionality. In many cases there is a requirement for the presence of a specific functional group within the substrate, thereby limiting its applicability in organic transformations. Most preferably, simple organic scaffolds that incorporate alcohol or amine functions will be preferred to lift the potential of substrate-controlled $\mathrm{CO}_{2}$ conversion, and the ubiquitous presence of such groups in basic chemicals provides a hopeful starting point. Another important aspect is the development of suitable organocatalysts within this field of chemistry. While organocatalysts have already been successfully implemented in several (simple) $\mathrm{CO}_{2}$ transformations, ${ }^{10 \mathrm{c}}$ other sub-areas in $\mathrm{CO}_{2}$ conversion are still mainly dominated by metal based systems. In addition, the range of products that can be obtained through $\mathrm{CO}_{2}$ activation by the substrate needs to be expanded to mature this conceptual approach. The synthesis of quinazolines, iso-benzofurans and ureas are nice examples of further product diversification that can be achieved. The development of new catalysts and methodologies will certainly add further exciting examples to this rapidly developing area of $\mathrm{CO}_{2}$ valorization.

\section{Acknowledgment}

We thank ICIQ, ICREA, and the Spanish Ministerio de Economía y Competitividad (MINECO) through project CTQ2014-60419-R, and further support through Severo Ochoa Excellence Accreditation 20142018 (SEV-2013-0319). JR thanks ICIQ for a predoctoral fellowship.

\section{References}

(1) Friedlingstein, P.; Andrew, R. M.; Rogelj, J.; Peters, G. P.; Canadell, J. G.; Knutti, R.; Luderer, G.; Raupach, M. R.; Schaeffer, M; van Vuuren, D. P.; Le Quere, C. Nat. Geosci. 2014, 7, 709.

(2) (a) Lim, X. Nature 2015, 520, 628. (b) van den Assen, N.; Müller, L. J.; Steingrube, A.; Voll, P.; Bardow, A. Environ. Sci. Technol. 2016, 50, 1093. (c) Liu, Q.; Wu, L.; Jackstell, R.; Beller, M. Nat. Commun. 2015, 6, 5933.

(3) Aresta, M.; Dibenedetto, A.; Angelini, A. Chem. Rev. 2014, 114, 1709.

(4) Aresta, M.; Dibenedetto, A.; Angelini, A. J. $\mathrm{CO}_{2}$ Utiliz. 2013, 3-4, 65.

(5) Omae, I. Coord. Chem. Rev. 2012, 256, 1384.

(6) Biochemistry, $5^{\text {th }}$ ed., eds. Berg, J.M., Tymoczko, J. L. and Stryer, L., W. H. Freeman, NY 2002.

(7) Kelsey, R. A.; Miller, D. A.; Parkin, S. R.; Liu, K.; Remias, J. E.; Yang, Y.; Lightstone, F. C.; Liu, K.; Lippert, C. A.; Odom, S. A. Dalton Trans. 2016, 45, 324.

(8) (a) Zhang, X.; van Eldik, R.; Koike, T.; Kimura, E. Inorg. Chem. 1993, 32, 5749. (b) Zhang, X.; van Eldik, R. Inorg. Chem. 1995, 34, 5606.

(9) (a) Moller, F.; Merz, K.; Herrmann, C.; Apfel, U. P. Dalton Trans. 2016, 45, 904. (b) Bandeira, N. A. G.; Garai, S.; Müller, A.; Bo, C. Chem. Commun. 2015, 51, 15596.

(10) (a) Werner, T.; Tenhumberg, N. J. $\mathrm{CO}_{2}$ Utiliz. 2014, 7, 39. (b) Alves, M.; Grignard, B.; Gennen, S.; Mereau, R.; Detrembleur, C., Jerome, C.; Tassaing, T. Catal. Sci. Technol. 2015, 5, 4636. (c) Fiorani, G.; Guo, W.; Kleij, A. W. Green Chem. 2015, 17, 1375. 
(11) West, K. N.; Wheeler, C.; McCarney, J. P.; Griffith, K. N.; Bush, D.; Liotta, C. L.; Eckert, C. A., J. Phys. Chem. A 2001, 105, 3947.

(12) Gassensmith, J. J.; Furukawa, H.; Smaldone, R. A.; Forgan, R. S.; Botros, Y. Y.; Yaghi, O. M.; Stoddart, J. F. J. Am. Chem. Soc. 2011, 133, 15312.

(13) Martín, C.; Fiorani, G.; Kleij, A. W. ACS Catal. 2015, 5, 1353.

(14) (a) Hara, Y.; Onodera, S.; Kochi, T.; Kakiuchi, K. Org. Lett. 2015, 17, 4850. (b) Toullec, P.; Carbayo Martin, A.; Gio-Batta, M.; Bruneau, C.; Dixneuf, P. H. Tetrahedron Lett. 2000, 41, 5527.

(15) (a) Gendre, P. L.; Thominot, P.; Bruneau, C.; Dixneuf, P. H. J. Org. Chem. 1998, 63, 1806. (b) Ohe, K.; Matsuda, H.; Morimoto, T. Ogoshi, S.; Chatani, N.; Murai, S. J. Am. Chem. Soc. 1994, 116, 4125.

(16) DE1098953, Dimroth, P.; Pasedach, H. 1961.

(17) Laas, H.; Nissen, A.; Nürrenbach, A. Synthesis 1981, 958.

(18) Iritani, K.; Yanagihara, N.; Utimoto, K. J. Org. Chem. 1986, 51, 5499.

(19) Inoue, Y.; Ishikawa, J.; Taniguchi, M.; Hashimoto, H. Bull. Chem. Soc. Jpn. 1987, 60, 1204.

(20) Sasaki, Y. Tetrahedron Lett. 1986, 27, 1573.

(21) (a) Kim, H.-S.; Kim, J.-W.; Kwon, S.-C.; Shim, S.-C.; Kim, T.-J. J. Organomet. Chem. 1997, 545-546, 337. (b) Jiang, H.-F.; Wang, A. Z.; Liu, H.-L.; Qi, C.-R. Eur. J. Org. Chem. 2008, 2309. (c) Gu, Y.; Shi, F.; Deng, Y. J. Org. Chem. 2004, 69, 391.

(22) Ouyang, L.; Tang, X.; He, H.; Qi, C.; Xiong, W.; Ren, Y.; Jiang, H. Adv. Synth. Catal. 2015, 357, 2556.

(23) Minakata, S.; Sasaki, I.; Ide, T. Angew. Chem. Int. Ed. 2010, 49, 1309.

(24) Yamada, W.; Sugawara, Y.; Cheng, H. M.; Ikeno, T.; Yamada, T. Eur. J. Org. Chem. 2007, 2604.

(25) Yoshida, S.; Fukui, K.; Kikuchi, S.; Yamada, T. J. Am. Chem. Soc. 2010, $132,4072$.

(26) (a) Tang, X.; Qi, C.; He, H.; Jiang, H.; Ren, Y.; Yuan, G. Adv. Synth. Catal. 2013, 355, 2019. (b) Cui, M.; Qian, Q.; He, Z.; Ma, J.; Kang, X.; Hu, J.; Liu, Z.; Han, B. Chem. Eur. J. 2015, 21, 15924.

(27) (a) Yang, Z.-Z.; Zhao, Y.; Zhang, H.; Yu, B.; Ma, Z.; Ji, G.; Liu, Z. Chem. Commun. 2014, 50, 13910. (b) Yang, Z.; Yu, B.; Zhang, H.; Zhao, Y.; Chen, Y.; Ma, Z.; Ji, G.; Gao, X.; Han, B.; Liu, Z. ACS Catal. 2016, 6, 1268.

(28) (a) Song, Q.-W.; Chen, W.-Q.; Ma, R.; Yu, A.; Li, Q.-Y.; Chang, Y.; He, L.-N. ChemSusChem 2015, 8, 821. (b) Song, Q.-W.; He, L.-N. Adv. Synth. Catal. 2016, 358, 1251. (c) Song, Q.-W.; Yu, B.; Li, X.-D.; Ma, R.; Diao, Z.-F.; Li, R.-G.; Li, W.; He, L.-N. Green Chem. 2014, 16, 1633.

(29) Kimura, T.; Kamata, K.; Mizuno, N. Angew. Chem. Int. Ed. 2012, 51, 6700.

(30) Hu, J.; Ma, J.; Zhu, Q.; Qian, Q.; Han, H.; Mei, Q.; Han, B. Green Chem. 2016, 18, 382

(31) (a) Dixneuf, P. H. Catal. Lett. 2014, 145, 360. (b) Qing-Wen, S.; He, L.-N. in Advances in $\mathrm{CO}_{2}$ Capture, Sequestration, and Conversion, American Chemical Society, 2015, 1194, 47. (c) S. Kikuchi, T. Yamada, The Chemical Record 2014, 14, 62.

(32) Fournier, J.; Bruneau, C.; Dixneuf, P. H. Tetrahedron Lett. 1989, 30, 3981.

(33) (a) Joumier J. M.; Fournier, J.; Bruneau, C.; Dixneuf, J. Chem. Soc., Perkin Trans. 1 1991, 3271. (b) Bruneau, C.; Dixneuf, P. H. J. Mol. Catal. 1992, 74, 97.

(34) Kayaki, Y.; Yamamoto, M.; Ikariya, T. J. Org. Chem. 2007, 72, 647.

(35) Jung, M. E.; Gervay, J. J. Am. Chem. Soc. 1991, 113, 224.

(36) Qi, C.; Huang, L.; Jiang, H. Synthesis 2010, 1433.

(37) Uemura, K.; Kawaguchi, T.; Takayama, H.; Nakamura, A.; Inoue, Y.J. Mol. Catal. A: Chem. 1999, 139, 1.

(38) Ca, N. D.; Gabriele, B.; Ruffolo, G.; Veltri, L.; Zanetta, T.; Costa, M. Adv. Synth. Catal. 2011, 353, 133.

(39) Wang, Y.-B.; Sun, D.-S.; Zhou, H.; Zhang, W.-Z.; Lu, X.-B. Green Chem. 2014, 16, 2266.

(40) (a) Kayaki, Y.; Yamamoto, M.; Ikariya, T. Angew. Chem. Int. Ed. 2009, 48, 4194. (b) Tommasi, I.; Sorrentino, F. Tetrahedron Lett. 2009, 50, 104.

(41) Wang, Y.-B.; Wang, Y.-M.; Zhang, W.-Z.; Lu, X.-B. J. Am. Chem. Soc. 2013, 135, 11996.
(42) (a) Heravi, M. M.; Zadsirjan, V. Tetrahedron: Asymmetry 2013, 24, 1149. (b) Evans, D. A.; Ennis, M. D.; Le, T.; Mandel, N.; Mandel, G. J. Am. Chem. Soc. 1984, 106, 1154.

(43) Sarkar, A.; Bhattacharyya, S.; Dey, S. K.; Karmakar, S.; Mukherjee, A. New J. Chem. 2014, 38, 817.

(44) Giovanni, Z.; Pilar, M.; Giuliano Delle, M.; Domenico, M.; Laura, N.; Bruno, B. Mini-Reviews in Med. Chem. 2007, 7, 389.

(45) Aurelio, L.; Brownlee, R. T. C.; Hughes, A. B. Chem. Rev. 2004, 104, 5823.

(46) Kim, T.-J.; Kwon, K.-H.; Kwon, S.-C.; Baeg, J.-O.; Shim, S.-C.; Lee, D.H. J. Organomet. Chem. 1990, 389, 205.

(47) (a) Mahé, R.; Dixneuf, P. H.; Lécolier, S. Tetrahedron Lett. 1986, 27, 6333. (b) Sasaki, Y.; Dixneuf, P. H. J. Chem. Soc., Chem. Commun. 1986, 790. (c) Sasaki, Y.; Dixneuf, P. H. J. Org. Chem. 1987, 52, 314.

(48) Costa, M.; Chiusoli, G. P.; Rizzardi, M. Chem. Commun. 1996, 1699.

(49) Yoshida, S.; Fukui, K.; Kikuchi, S.; Yamada, T. Chem. Lett. 2009, 38, 786.

(50) Hase, S.; Kayaki, Y.; Ikariya, T. Organometallics 2013, 32, 5285.

(51) (a) Shi, M.; Shen, Y.-M. J. Org. Chem. 2002, 67, 16. (b) Bacchi, A.; Chiusoli, G. P.; Costa, M.; Gabriele, B.; Righi, C.; Salerno, G. Chem. Commun. 1997, 1209.

(52) Costa, M.; Chiusoli, G. P.; Taffurelli, D.; Dalmonego, G. J. Chem. Soc., Perkin Trans. 1 1998, 1541.

(53) Hu, J.; Ma, J.; Zhang, Z.; Zhu, Q.; Zhou, H.; Lu, W.; Han, B. Green Chem. 2015, 17, 1219.

(54) Kayaki, Y.; Yamamoto, M.; Suzuki, T.; Ikariya, T. Green Chem. 2006 8, 1019.

(55) Garcia-Dominguez, P.; Fehr, L.; Rusconi, G.; Nevado, C. Chem. Sci. 2016, 7, 3914.

(56) Deng, Z.; Wei, J.; Liao, L.; Huang, H.; Zhao, X. Org. Lett. 2015, 17 1834.

(57) G. Cardillo, M. Orena, G. Porzi, S. Sandri, J. Chem. Soc., Chem. Commun. 1981, 465

(58) Wu, X.; Gao, Q.; Lian, M.; Liu, S.; Wu, A. RSC Adv. 2014, 4, 51180.

(59) Tanner, D. D.; Gidley, G. C.; Das, N.; Rowe, J. E.; Potter, A. J. Am. Chem. Soc. 1984, 106, 5261.

(60) Glover, S. A.; Goosen, A. Tetrahedron Lett. 1980, 21, 2005.

(61) Minakata, S. Acc. Chem. Res. 2009, 42, 1172.

(62) Usami, K.; Nagasawa, Y.; Yamaguchi, E.; Tada, N.; Itoh, A. Org. Lett. 2016, $18,8$.

(63) Tang, S.; Liu, K.; Long, Y.; Gao, X.; Gao, M.; Lei, A. Org. Lett. 2015, 17 2404.

(64) Vara, B. A.; Struble, T. J.; Wang, W.; Dobish, M. C.; Johnston, J. N. J. Am. Chem. Soc. 2015, 137, 7302.

(65) Jensen, A. E.; Knochel, P. J. Org. Chem. 2002, 67, 79.

(66) (a) Yoshida, Y.; Inoue, S. Chem. Lett. 1977, 6, 1375. (b) McGhee, W. D.; Riley, D. P. Organometallics 1992, 11, 900.

(67) Cardillo, G.; Orena, M.; Sandri, S. J. Org. Chem. 1986, 51, 713.

(68) Toda, T.; Kitagawa, Y. Angew. Chem. Int. Ed. Engl. 1987, 26, 334.

(69) (a) Fernández, I.; Muñoz, L. Tetrahedron: Asymm. 2006, 17, 2548. (b) García-Egido, E.; Fernández, I.; Muñoz, L. Synth. Commun. 2006, 36, 3029.

(70) Takeda, Y.; Okumura, S.; Tone, S.; Sasaki, I.; Minakata, S. Org. Lett. 2012, 14, 4874.

(71) Shu, J.; He, L.; Ding, H.; Wang, L.; Guo, H.; Gao, Y.; Dzakah, E. E.; Zeng, Z. Anal. Meth. 2014, 6, 2306.

(72) Barbosa, J.; Freitas, A.; Moura, S.; Mourão, J. L.; Noronha da Silveira, M. I.; Ramos, F. J. Agric. Food. Chem. 2011, 59, 11927.

(73) Yoshida, M.; Ohsawa, Y.; Sugimoto, K.; Tokuyama, H.; Ihara, M. Tetrahedron Lett. 2007, 48, 8678.

(74) Soldi, L.; Massera, C.; Costa, M.; Della Ca', N. Tetrahedron Lett. 2014 $55,1379$.

(75) (a) Decortes, A.; Castilla, A. M.; Kleij, A. W. Angew. Chem. Int. Ed. 2010, 49, 9822. (b) Kathalikkattil, A. C.; Babu, R.; Tharun, J.; Roshan, R.; Park, D.-W. Catal. Surv. Asia 2015, 19, 223. (c) Cokoja, M.; Wilhelm, M. E.; Anthofer, M. H.; Herrmann, W. A.; Kühn, F. E. ChemSusChem 2015, 8, 2436. (d) Comerford, J. W.; Ingram, I. D. V.; North, M.; Wu, X. Green Chem. 2015, 17, 1966. 
(76) Rintjema, J.; Epping, R.; Fiorani, G.; Martín, E; Escudero-Adán, E. C.; Kleij, A. W. Angew. Chem. Int. Ed. 2016, 55, 3972.

(77) Kojima, F.; Aida, T.; Inoue, S. J. Am. Chem. Soc. 1986, 108, 391.

(78) Shang, J.; Guo, X.; Li, Z.; Deng, Y. Green Chem. 2016, 18, 3082.

(79) McCombie, S. W.; Metz, W. A. Tetrahedron Lett. 1987, 28, 383.

(80) (a) Myers, A. G.; Widdowson, K. L. Tetrahedron Lett. 1988, 29, 6389. (b) Myers, A. G.; Proteau, P. J.; Handel, T. M. J. Am. Chem. Soc. 1988, 110, 7212.

(81) Inkster, J. A. H.; Ling, I.; Honson, N. S.; Jacquet, L.; Gries, R.; Plettner, E. Tetrahedron: Asymm. 2005, 16, 3773.

(82) Ishii, S.; Zhou, M.; Yoshida, Y.; Noguchi, H. Synth. Commun. 1999, $29,3207$.

(83) Ishida, N.; Shimamoto, Y.; Murakami, M. Angew. Chem. Int. Ed. 2012, 51, 11750 .

(84) Gold, E. H. J. Am. Chem. Soc. 1971, 93, 2793.

(85) Rintjema, J.; Guo, W.; Martin, E.; Escudero-Adán, E. C.; Kleij, A. W. Chem. Eur. J. 2015, 21, 10754.

(86) Yoshida, Y.; Ishii, S.; Yamashita, T. Chem. Lett. 1984, 13, 1571.

(87) (a) Salvatore, R. N.; Chu, F.; Nagle, A. S.; Kapxhiu, E. A.; Cross, R. M.; Jung, K. W. Tetrahedron 2002, 58, 3329. (b) Shi, M.; Shen, Y.-M. Molecules 2002, 7, 386.

(88) Oi, S.; Nemoto, K.; Matsuno, S.; Inoue, Y. Macromol. Rapid Commun. 1994, 15, 133.
(89) (a) Yan, P.; Tan, X.; Jing, H.; Duan, S.; Wang, X.; Liu, Z. J. Org. Chem. 2011, 76, 2459. (b) Reithofer, M. R.; Sum, Y. N.; Zhang, Y. Green Chem. 2013, 15, 2086.

(90) Soga, K.; Hosoda, S.; Nakamura, H.; Ikeda, S. J. Chem. Soc., Chem. Commun. 1976, 617.

(91) Kawanami, H.; Matsumoto, H.; Ikushima, Y. Chem. Lett. 2005, 34, 60.

(92) Gao, J.; Song, Q.-W.; He, L.-N; Liu, C.; Yang, Z.-Z.; Han, X.; Li, X.-D.; Song, Q.-C. Tetrahedron 2012, 68, 3835.

(93) Adhikari, D.; Miller, A. W.; Baik, M.-H.; Nguyen, S. T. Chem. Sci. 2015 6, 1293.

(94) (a) Kathalikkattil, A. C.; Tharun, J.; Roshan, R.; Soek, H.-G.; Park, D.W. Appl. Catal. A: Gen. 2012, 447-448, 107. (b) Takeda, Y.; Kawai, H.; Minakata, S. Chem. Eur. J. 2013, 19, 13479. (c) Wu, Y.; Liu, G.; Tetrahedron Lett. 2011, 52, 6450. (d) Jiang, H.-F.; Ye, J.-W.; Qi, C.-R.; Huang, L.-B. Tetrahedron Lett. 2010, 51, 928.

(95) C. Phung, R. M. Ulrich, M. Ibrahim, N. T. G. Tighe, D. L. Lieberman, A. R. Pinhas, Green Chemistry 2011, 13, 3224-3229.

(96) Nale, D. B.; Saigaonkar, S. D.; Bhanage, B. M. J. $\mathrm{CO}_{2}$ Utiliz. 2014, 8 , 67.

(97) Ishida, T.; Kikuchi, S.; Tsubo, T.; Yamada, T. Org. Lett. 2013, 15, 848

(98) Yamashita, K.; Hase, S.; Kayaki, Y.; Ikariya, T. Org. Lett. 2015, 17 2334. 


\section{Biosketches}

Arjan W. Kleij received his MSc (1996) and PhD (2000) from the University of Utrecht (The
Netherlands) under the supervision of Professor Gerard van Koten working on the application of
metallodendrimers in homogeneous catalysis. In the next six years, he held various positions
including two in industry at Avantium Technologies as a project leader in its pharma division, and at
Hexion Specialty Chemicals as a R\&D scientist concerned with process chemistry in the area of epoxy
resins and precursors. He also held two postdoctoral positions at the UAM (Madrid, 2002) working
with Professor Javier de Mendoza in the area of calixarene chemistry, and with Professor Joost Reek
at the University of Amsterdam (2003-2005) focusing on supramolecular catalysis. In 2006, he took
a position as Group Leader at the Institute of Chemical Research of Catalonia (ICIQ) and ICREA
fellow, and was promoted to ICREA professor in 2011. His research focuses on the use of carbon
dioxide/functional carbonates as reagents in organic and new (bio)polymer synthesis using metal-
and organo-catalyzed strategies.

Jeroen Rintjema studied chemistry at the University of Amsterdam (The Netherlands) where he
received his BSc (2009) and his MSc (2011). During this time, he developed new supramolecular gold
chemistry under the supervision of Prof. Joost Reek. Since 2013, he joined the group of Arjan Kleij in
ICIQ as a PhD student working on carbon dioxide conversion catalysis. His research specifically focuses
on the development of new synthetic methods utilizing substrate-mediated $\mathrm{CO}_{2}$ activation strategies.

